\title{
Disentangling the Effects of Cognitive Development and Linguistic Expertise: A Longitudinal Study of the Acquisition of English in Internationally- Adopted Children
}

\section{Citation}

Snedeker, Jesse, Joy Geren, and Carissa L. Shafto. Forthcoming. Disentangling the effects of cognitive development and linguistic expertise: A longitudinal study of the acquisition of English in internationally-adopted children. Cognitive Psychology.

\section{Permanent link}

http://nrs.harvard.edu/urn-3:HUL.InstRepos:5149081

\section{Terms of Use}

This article was downloaded from Harvard University's DASH repository, and is made available under the terms and conditions applicable to Open Access Policy Articles, as set forth at http:// nrs.harvard.edu/urn-3:HUL.InstRepos:dash.current.terms-of-use\#OAP

\section{Share Your Story}

The Harvard community has made this article openly available.

Please share how this access benefits you. Submit a story.

\section{Accessibility}


Running Head: INTERNATIONAL ADOPTION AND LANGUAGE DEVELOPMENT

Disentangling the effects of cognitive development and linguistic expertise: A longitudinal study of the acquisition of English in internationally-adopted children.

\author{
Jesse Snedeker ${ }^{1}$, Joy Geren ${ }^{1}$ and Carissa L. Shafto ${ }^{2}$ \\ ${ }^{1}$ Harvard University \\ ${ }^{2}$ University of Louisville
}

(Accepted pending revision, Cognitive Psychology)

Address Correspondence to:

Jesse Snedeker

1136 WJH, 33 Kirkland St.

Cambridge MA, 02138

Phone: 617-495-3873; fax: 617-384-7944

snedeker@wjh.harvard.edu 


\begin{abstract}
Early language development is characterized by predictable changes in the words children produce and the complexity of their utterances. In infants these changes could reflect increasing linguistic expertise or cognitive maturation and development. To disentangle these factors, we compared the acquisition of English in internationally-adopted preschoolers and internationallyadopted infants. Parental reports and speech samples were collected for one year. Both groups showed the qualitative shifts that characterize first-language acquisition. Initially, they produced single-word utterances consisting mostly of nouns and social words. The appearance of verbs, adjectives and multiword utterances was predicted by vocabulary size in both groups. Preschoolers did learn some words at an earlier stage than infants, specifically words referring to the past or future and adjectives describing behavior and internal states. These findings suggest that cognitive development plays little role in the shift from referential terms to predicates but may constrain children's ability to learn some abstract words.
\end{abstract}

Keywords: language development, international adoption, word learning, one-word stage, language production, nouns, verbs. 
Early language production can be characterized as a series of roadblocks that are gradually removed. Most infants use single-word utterances for many months before they begin combining words (Nice, 1925; Bloom, 1973). Children's first words are largely limited to social routines and labels for the people and things around them. Verbs, adjectives and closed-class words only become common at larger vocabulary sizes (Doran, 1907; McCarthy, 1930; Gentner, 1982, Bates, Marchman, Thal, Fenson, Dale, Reznick, et al., 1994). Two central questions in language acquisition are: What accounts for these early limitations, and how are they overcome (Lenneberg, 1967; Bloom, 1973; Cromer, 1974; Gleitman, 1981)? Specifically, are the initial stages present because the child is cognitively or perceptually immature, or do they represent necessary steps in decoding the target language? Are new linguistic abilities partially due to broad changes in the cognitive abilities of the learner, or are they solely attributable to the child's growing knowledge of the language itself? These questions are difficult to answer because cognitive development and language acquisition are confounded in typically developing children. Young infants are cognitively immature and limited in their linguistic knowledge, while older children are more sophisticated in both respects.

When confronted with confounds like this, developmental psychologists often turn to special populations in which the variables of interest can be disentangled. Much of what we know about language development comes from studies of atypical populations (see e.g., Bellugi, Marks, Bihrle \& Sabo, 1988; Cromer, 1974; Curtiss, 1989; Goldin-Meadow \& Feldman, 1977; Landau \& Gleitman, 1985; Senghas, 2003). These natural experiments allow us to explore the effects of factors that are impossible or unethical to manipulate.

International adoption is one such natural experiment, creating the opportunity to disentangle the effects of linguistic expertise and cognitive maturation (Snedeker, Geren \& 
Shafto, 2007). About 17,000 internationally-adopted children enter the U.S. each year (U.S. Department of State, 2008). While most are infants or toddlers, thousands of older children are also adopted. Many of these children are well within the critical or sensitive period for learning language (Newport, 1990). These older children appear to rapidly lose their birth language (Glennen \& Masters, 2002) and become fluent speakers of their adoptive language (Pallier, et al., 2003). But we know almost nothing about how they get there. While a number of researchers have studied language development in children adopted as infants or toddlers (see e.g., Glennen \& Masters, 2002; Roberts, Pollock, Krakow, Price, Fulmer \& Wang, 2005; Pollock, 2005), there is little work on acquisition in children who were adopted after 30 months.

The learning problem faced by internationally-adopted preschoolers is broadly similar to that of infants learning their first language: they are exposed to child-directed speech in the context of daily routines; they must learn the new language to communicate with their families; they have little access to text or bilingual informants; and they lack many of the metalinguistic skills available to older children and adults (Gombert, 1992). However, these children are more cognitively and physically mature than their infant counterparts and have already started to learn one language. Thus international adoption could provide a way to explore the role that cognitive development and maturation play in shaping the course of first language acquisition, by allowing us to see how acquisition proceeds when these roadblocks have been removed. Such a tool would be useful for distinguishing between two broad classes of hypotheses about qualitative changes during language acquisition:

1) Developmental Hypotheses: Theories of this kind attribute the order of acquisition or the emergence of new abilities to changes in the learner that are independent of her experience with a given language. Immaturity constrains language acquisition, limiting the kinds of words that a 
child can learn, the kinds of utterances she can produce or the kinds of representations she can create. When these limitations are removed, by biological maturation or cognitive development, new linguistic abilities can emerge.

2) Contingent-Acquisition Hypotheses: These theories attribute the order of acquisition to the interdependence of different linguistic representations, processes, and learning algorithms. Critically, the emergence of new abilities is driven by the child's growing knowledge of the language. If knowledge of form $\mathrm{A}$ is necessary for acquiring form $\mathrm{B}$, then the acquisition of $\mathrm{B}$ will have to await the acquisition of A. ${ }^{1}$

Critically, this distinction is orthogonal to the nativist/empiricist and domainspecific/domain-general dichotomies that typically organize theoretical discussions of language development. Contingent-acquisition hypotheses necessarily attribute shifts to the child's growing knowledge of the language, but they differ in their claims about how the child acquires that knowledge in the first place. Thus there are contingent-acquisition hypotheses which invoke innate language-specific representations and highly-constrained learning mechanisms (e.g., Snedeker \& Gletiman, 2004) and others which posit that language acquisition is largely driven by domain-general learning abilities (e.g., Bates \& Goodman, 1997). The developmental hypotheses are even more diverse. For example, Wexler has argued that the development of tense and agreement depends on the maturation of domain-specific innate syntactic knowledge (Wexler, 1999). In contrast, others have suggested that the length of children's early utterances depends on a domain-general increase in memory capacity (see e.g., Shore, 1986). These two proposals differ in the mechanisms they invoke and the phenomena they seek to explain, yet both are developmental hypotheses because they attribute changes in linguistic abilities to events that

\footnotetext{
${ }^{1}$ The contingent-acquisition hypotheses under consideration make the weaker claim that one type of knowledge is needed for efficient acquisition or utilization of another type. This is desirable since the generalizations under consideration are strong but violable. For example, children do learn some verbs early on (Bates et al. 1995).
} 
are distinct from the process of language acquisition itself and are tightly linked to the child's biological or cognitive development. Consequently, both theories predict that older learners, with mature grammars and longer memory spans, would initially produce more complete utterances than young children who begin acquiring the language in infancy.

Our work tests central predictions of developmental hypotheses by tracking the early language development of internationally-adopted children. Developmental hypotheses deal with diverse phenomena, ranging from the timing of babbling in infancy to the mastery of complex constructions during the early school years, thus no single method or population can be used to address all of these proposals. In the present study, we focus on two qualitative changes that typically occur between 12 and 30 months of age: 1) the systematic shift in the composition of the child's lexicon from concrete nouns to more abstract words such as verbs, adjectives and grammatical function words and 2) the end of the one-word stage and the emergence of combinatorial speech. These phenomena were selected because they are robust, easy to observe and central to theories about children's early word learning and language production.

In the remainder of this introduction, we examine these two shifts in greater detail. For each one, we describe the relevant developmental and contingent-acquisition hypotheses and briefly review the prior research. We conclude that the evidence to date is consistent with both classes of explanation. Finally, we describe our initial work on language acquisition in internationallyadopted children (Snedeker et al., 2007) laying out the motivations for the present study. 


\section{Accounting for changes in early vocabulary composition}

Children's early vocabularies are dominated by social routines ("bye bye") and nouns that refer to people, animals, and small moveable objects. Although adults speak to children in full sentences, complete with verbs and grammatical function words, these elements are massively underrepresented in children's early vocabularies (Gentner, 1982, Bates et al., 1994; Behrens, 2006). As children's lexicons grow the proportion of social words declines and more verb, adjectives and function words appear, resulting in systematic correlations between vocabulary size and vocabulary composition (Bates et al., 1994). These systematic shifts lend themselves to both developmental accounts and contingent-acquisition hypotheses (see Conboy \& Thal, 2006).

Developmental accounts of vocabulary shifts appeal to a range of mechanisms. For example, some theorists have suggested that the skewed nature of children's early lexicons may reflect their conceptual limitations (Huttenlocher, Smiley \& Ratner, 1983; O’Grady, 1987). Perhaps the relative dearth of verbs and adjectives is attributable to the infant's inability to conceive of relations, states or actions, while the overabundance of nouns is attributable to the conceptual primacy of object categories. As children overcome these limitations and develop the relevant concepts, they are able to acquire the words that encode them. This account provides a particularly intuitive explanation for young children's failure to learn words, like mental state verbs or temporal connectives, that are very frequent, highly abstract, and known to cause conceptual difficulties later in childhood.

The maturation of perceptual mechanisms could also play a role in the diversification of vocabulary. Closed-class words (or function words) are typically short in duration, rarely receive stress, and often have reduced vowels (Morgan, Shi \& Allopena, 1996; Selkirk, 1996). These factors could make them difficult for infants to accurately perceive or produce, raising the 
possibility that their emergence between 24 and 30 months is caused by improvements in perception or motor control.

But the changing composition of children's lexicons is equally amenable to contingentacquisition hypotheses. For example, Gleitman and her colleagues have argued that shifts in lexical composition reflect the child's growing mastery of a particular language, rather than conceptual or perceptual development (Gillette et al., 1999; Snedeker \& Gleitman, 2004; Gleitman, Cassidy, Papafragou, Nappa \& Trueswell, 2005). An infant who is just breaking into language can only learn the meanings of words by observing the situational contexts in which they are used. This information may be sufficient for learning social routines, names for people, and labels for objects, because the meanings of these words can be readily inferred from nonlinguistic social cues (e.g., points or eye gaze). But as the child's knowledge of language grows, she is increasingly able to decode the sentence in which a new word appears and use this information to infer its meaning. This strategy (syntactic bootstrapping) could allow her to acquire more abstract relational words, such as verbs, adjectives and closed-class items. Perceptual bootstrapping could also play a role in vocabulary diversification. Closed-class words rarely appear in isolation (Brent \& Siskind, 1999), instead they are typically part of the same prosodic unit as an adjacent open-class word (Selkirk, 1996). Thus stable representations of open-class words may be necessary for the accurate segmentation (and acquisition) of many closed-class words.

Although vocabulary composition is a well-studied topic, only a few lines of research appear to bear on the distinction between developmental and contingent-acquisition hypotheses. First, there is an extensive literature documenting that early vocabulary composition varies across linguistic and cultural contexts. Specifically, children who are learning object-dropping 
languages like Mandarin or Korean produce more verbs early in development than those who are learning languages like English (Tardif, 1996; Choi \& Gopnik, 1995). If a given ability emerges early in one language and late in another, it seems reasonable to conclude that its emergence in the later language cannot be attributed to cognitive or maturational changes. There are two reasons, however, to reject this conclusion. First, the phenomenon of interest appears to be universal - under the correct description. As Gentner points out, the relevant question is not whether every child knows more nouns than verbs, but rather whether children systematically learn more nouns than we would expect given their frequency in the input (Gentner \& Boroditsky, 2001). If the noun bias is characterized in this way, the current evidence suggests that it is a cross-linguistically robust feature of development (see e.g., Kim, McGregor \& Thompson, 2000; Tardif, Gelman \& Xu, 1999; Bornstein et al., 2004). Second, it is possible for shifts which are specific to particular languages to be caused by universal developmental changes. For example, suppose that the acquisition of function words in languages like English is driven by the maturation of perceptual abilities that allow children to accurately represent reduced syllables at the beginning of a phonological phrase. This skill would be unnecessary in languages in which function words have full vowels or appear at the end of phonological phrases. Consequently, the age at which function words appeared would vary across languages, but their emergence in English would (by hypothesis) depend on perceptual maturation.

A second line of research has explored the contingent-acquisition hypothesis by simulating the effects of linguistic development in the absence of cognitive limitations. In a series of studies, Gleitman and her colleagues asked adults to identify common words from different representations of the contexts in which they occurred in child-directed speech (Gillette et al., 1999; Snedeker \& Gleitman, 2004). When limited to situational cues, adults could only identify 
the concrete nouns. However, when they were given information about the linguistic context, they were able to learn abstract nouns and verbs as well. These experiments demonstrate that changes in vocabulary composition are not necessarily attributable to changes in the learner's conceptual repertoire. But there are several differences between these human simulation experiments and the experiences of young language learners which might limit their validity. The adult observers are not participants in the interactions, which may affect both their level of motivation and their access to information about the participants' goals. Unlike infants, the participants in these studies do not have to segment utterances or create a representation of the phonological form of the word. While young children must simultaneously grapple with several unknown words, the adults in these studies were given massed presentations of each target item, drastically reducing the memory demands of the task. If these differences merely improve or hinder performance equally for words of all kinds, then the simulations would still allow us to conclude that situational cues are more informative for nouns than for verbs. However, if these factors have differential effects on words of different classes, then such studies may not provide the relevant characterization of the input.

In contrast, the task and input of the adopted child appear to closely parallel that of the typically developing infant. Like the infant, the adopted child gets prolonged exposure to her new language in the context of meaningful social interactions. Like the infant she must simultaneously isolate the words and determine what they mean. However, like the adults in the human simulations, the adopted child is cognitively more mature than the infant. If shifts in vocabulary composition primarily reflect the changing cognitive capacities of the learner, then adopted children should acquire words from a variety of categories, much like their monolingual 
age mates. If vocabulary composition is largely a function of linguistic knowledge, then the adopted child should initially resemble the infant learner.

\section{The emergence of combinatorial speech}

For about four to six months after they begin speaking, children primarily produce singleword utterances. Short telegraphic utterances appear at about $16-19$ months of age, when the child has acquired a vocabulary of about 100 words (Nice, 1925; Bates, Dale \& Thal, 1995). Between 24 and 30 months, children's utterances continue to grow in complexity as they add determiners, auxiliaries and inflectional markers to their initially sparse statements (Brown, 1973). Both of these grammatical developments are tightly correlated with the child's productive vocabulary, suggesting that lexical and grammatical development are linked (Bates \& Goodman, 1997).

Two types of developmental hypotheses have been proposed to account for the development of combinatorial speech. Some theorists have suggested that the transition to multiword speech is driven by the development of a domain-general cognitive capacity to isolate and combine elements in novel ways (see e.g., Shore, 1986; Brownell, 1988). Others have argued that the onset of combinatorial speech depends on the maturation of a domain-specific grammatical capacity (Lenneberg, 1967; Locke, 1997).

However the onset of combinatorial speech could also reflect a pattern of contingent acquisition. The tight correlation between vocabulary size and the complexity of children's utterances raises the intriguing possibility that children may have to learn a critical mass of words before they are able to acquire the grammatical knowledge that they need to combine them. While this proposal has been associated with theories in which grammatical knowledge emerges from the lexicon (Bates \& Goodman, 1997), it is compatible with any theory of 
acquisition which proposes that lexical knowledge is essential for the creation (or proper identification) of grammatical representations (see e.g., Pinker, 1984; Tomasello, 1991; Locke, 1997; Redington, Chater \& Finch, 1999).

Two lines of research support a developmental hypothesis for the emergence of combinatorial speech. First, in typical children, this milestone in language acquisition is associated with milestones in other domains (Lenneberg, 1967). For example, combinatorial speech usually appears around the same time as symbolic play (Fenson \& Ramsay, 1980), block construction (Greenfield, 1978), sequenced imitation (McCall, Parke, Kavanaugh, 1977), and changes in nonverbal categorization (Sugarman, 1983). Many of these associations are reliable even when age is controlled or factored out. For example, Shore and colleagues found reliable correlations between the length of children's utterances at 20 months and the complexity of their symbolic play sequences (Shore, O'Connell \& Bates, 1984). Such findings have led many to suggest that combinatorial speech may have to await the development of some domain-general cognitive ability affecting memory, sequencing, or symbolic representation (Shore, 1986; Brownell, 1988; Bauer, Hertsgaard, Dropnik \& Daly, 1998).

Additional support for this developmental hypothesis comes from studies of early language acquisition in children with developmental disorders. Children with both Down syndrome and Williams syndrome show substantial delays in early language production which are roughly proportional to their cognitive delays, resulting in productive vocabularies that are roughly the size of mental age matched controls (Singer Harris, Bellugi, Bates, Jones, \& Rossen, 1997; Vicari, Caselli, Gagliardi, Tonucci \& Volterra, 2002; Laing et al., 2002). This early association between general cognitive ability and language production is quite robust; even mentally- 
retarded persons who go on to develop extraordinary linguistic skills appear to have had early language delays proportional to their cognitive impairments (Rondal, 2003).

In Williams syndrome, the onset and growth of combinatorial speech is also synchronized to vocabulary size and mental age, just as it is in typical children (Singer Harris et al., 1997; Vicari et al., 2002). In contrast, children with Down syndrome produce fewer and shorter combinations than typical children of the same mental age. These findings are consistent with the hypothesis that the onset of combinatorial speech is usually triggered by the development of a domaingeneral cognitive capacity closely linked to general intelligence. In typical development and in Williams syndrome, acquisition of this ability is sufficient for combinatorial speech. In children with Down syndrome, other impairments may stand in the way (or the critical cognitive skill itself is slow to develop).

However, while these findings are compatible with the developmental hypothesis, they do not provide definitive evidence for it. Patterns of association - in typical children or in developmental disorders - are consistent with multiple causal accounts. These associations could reflect effects of general cognitive development on language development, or they could reflect effects of linguistic abilities on nonlinguistic tasks. Alternatively, language and cognitive development could proceed along independent lines but still be associated, so long as the pace of development in each domain was sensitive to some of the same variables (e.g., differences in general learning abilities, neural efficiency or the pace of biological maturation).

Support for the contingent-acquisition hypothesis comes from studies exploring the close relation between vocabulary growth and the development of combinatorial speech. Bates and her colleagues have demonstrated that the same pattern of lexical grammatical synchrony which characterizes typical development is also present in early-talkers, late-talkers and children with 
Williams syndrome, suggesting that lexical learning may fuel syntactic development (Bates \& Goodman, 1997). These studies, however, cannot rule out the possibility that both aspects of language depend upon the development of some other cognitive ability, one which is accelerated for early-talkers, delayed for late-talkers, and proportional to mental age in children with Williams syndrome.

The goal of the present study is to test the contingent-acquisition hypothesis by examining the relation between lexical and grammatical development in children who acquiring English as preschoolers. If vocabulary acquisition and combinatorial speech are causally connected, then this relationship should persist in maturationally-advanced learners. In contrast, if the correlation is created by rate-limiting development in another domain, then it should be possible to find disassociations in older learners.

A similar motivation underlies two recent studies of language production in young SpanishEnglish bilinguals (Marchman, Martinez-Sussman \& Dale, 2004; Conboy \& Thal, 2006). Because bilingual children split their time between two languages, vocabulary growth in each language is often delayed relative to monolinguals. Thus bilingual learners could potentially be maturationally-advanced learners, reaching each stage of acquisition at a later age than monolinguals. Both studies used a parental report measure and found that bilinguals showed the same qualitative shifts during acquisition as monolinguals. While these results are consistent with the contingent-acquisition hypothesis, they do not provide a strong test of the developmental hypothesis. In both studies, the bilingual children had language skills within the normal range for monolinguals of their age and no information was provided about their cognitive abilities. $^{2}$

\footnotetext{
${ }^{2}$ For example, the mean English vocabulary size for the cross-sectional sample in Conboy \& Thal (2006) was 176 words at 20 months, a value which is near the median for English monolinguals (Fenson et al., 1993).
} 


\section{Our prior work and the goals of the present study}

To explore the role of cognitive development and maturation in these shifts, we conducted a preliminary study of the acquisition of English by internationally-adopted preschoolers (Snedeker et al., 2007). Parental reports and speech samples were collected from preschoolers, 3 to 18 months after they were adopted from China. The children showed the same qualitative shifts in language production as monolingual infants (matched for vocabulary size). Early on, their vocabularies were dominated by nouns, their utterances were short, and grammatical morphemes were generally omitted. Children at later stages had more diverse vocabularies and produced longer utterances with more grammatical morphemes.

This study had four limitations that are addressed in the present paper. First, the average participant had been in the U.S. for 8 months at the time of the first session, thus many of the children had already passed through the initial stages of language acquisition before data collection began. Second, the limited number of data points available for each child made it unclear whether these shifts characterized development on an individual level. Only $27 \%$ had data points spanning a range of 200 words or more, and thus the shifts in vocabulary composition that were observed in this study were primarily driven by differences across individuals. Third, in the previous study we did not collect any data that would allow us to verify that the children in the study were in fact more cognitively capable and physically mature than infants learning their first language. While this seems like a safe assumption, documentation would be helpful, particularly in light of delays that are associated with institutional care (Sloutsky, 1997). Fourth, in the previous study our control group consisted of typically developing infants learning English as a first language. Thus, the adopted preschoolers were not only older that the control children, they were also drawn from a different population and were being raised by parents who had 
chosen adoption and might differ in their linguistic behavior or parenting style. In the present study, we address this concern by using a control group of internationally-adopted infants.

\section{Methods}

\section{$\underline{\text { Participants }}$}

Information about the participants appears in Table 1. The preschool group consisted of nine children who had been adopted between $2 ; 6$ and 5;6 inclusive $(M=4 ; 0)$, while the infant group consisted of fourteen children who were adopted before 16 months of age $(\mathrm{M}=1 ; 0)$. Preschoolers were enrolled shortly after arriving, thus they were between $2 ; 7$ and $5 ; 8(\mathrm{M}=4 ; 1)$ at the beginning of the study. Infants began the study after they were speaking and they were between $1 ; 3$ and $1 ; 10(\mathrm{M}=1 ; 7)$ at the time of the first session.

Table 1

Only children adopted from China or from Slavic-speaking countries were recruited. All of the children were believed to have been primarily exposed to a dialect of Mandarin, Cantonese or Russian, though some of the children may have been exposed to regional languages as well. Information about the study appeared periodicals, online newsletters and discussion boards for families with adopted children. Two of the children ( $F \& G)$ were biological siblings who came from different orphanages but entered the U.S. at the same time.

Three exclusionary criteria were used for both the preschool and infant groups. First, we excluded any family in which the parent regularly used a language other than English with the child. Families attending weekly classes in which the birth language was used were not excluded. .Second, we excluded children who had been diagnosed with a major developmental disorder, 
including Downs syndrome, an autism spectrum disorder or mental retardation. Children who were reported to have developmental delays or language delays were not excluded, but this information was recorded (Table 1). We reasoned that if we excluded children who were perceived as delayed, we would run the risk of disqualifying children who were simply learning English at slower rate and thus overestimate the pace of language acquisition in this population. Third, children who had a sensory or motor impairment that might affect speech perception or production were excluded, including those with bilateral hearing loss or an uncorrected cleft palate. Children with hearing loss in one ear or with tubes for ear infections were not excluded.

Twenty-one infants and twenty preschoolers began the study. Fourteen infants and nine preschoolers completed the study; these children comprise the longitudinal sample described above. Three additional preschoolers completed all sessions but were excluded because of new information indicating that they did not meet our criteria (two families regularly used the child's birth language and one child was diagnosed with a severe bilateral hearing loss). An additional seven infants contributed between one and five sessions $(M=3.4)$ and an additional eight preschoolers contributed between one and four sessions $(M=2.4)$. Our analyses will focus on the longitudinal sample. However, to guard against the possibility that the children who completed the study were substantially different than those who did not, all analyses were also conducted on the entire data set, and unless otherwise noted the pattern of effects remained the same.

\section{$\underline{\text { Measures }}$}

All materials for the study were mailed to the parents who collected the data in their home. Four measures were used: a background questionnaire, the MacArthur-Bates Communicative Development Inventory 2 (CDI-2), videotaped speech samples, and a modified version of the 
Ages and Stages Questionnaire. The background questionnaire was based on one used by Glennen and Masters (2002) and Pollock (2005). It asked about the child's history and health, their level of proficiency in their birth language, their adoptive family, their current use of English and their native language, and their current language environment. This information was used to characterize our sample and to exclude children who did not meet our selection criteria.

We examined the early English development of the adopted children using the CDI-2 (Fenson et al., 1993). The CDI-2 is a parent report measure which includes a 680-item vocabulary checklist, questions about children's early word combinations and a forced-choice sentence-complexity measure which asks about the child's use of inflectional morphemes and closed-class words. The CDI-2 is normed for children 16 to 30 months of age. However, it has also been used to track language development in older children with limited language skills (Thal, O'Hanlon, Clemmons \& Frailin, 1999; Singer-Harris et al., 1997).

The speech samples were collected by the participating parent who was instructed to videotape herself interacting with her child two times a month for 30-40 minutes. Families were given a standard set of toys to use while making the recordings. The speech sample was transcribed and used to validate the parental report of the child's language use and linguistic environment.

Our fourth measure was a parental report of children's cognitive, social and motor development. This measure was based on the Ages and Stages Questionnaires (ASQ). The ASQ is a set of parental checklists that are used to screen children between 2 months and 6 years for developmental delays that might warrant clinical attention (Bricker \& Squires, 1999). The questions probe gross-motor, fine-motor, personal-social, problem solving and language skills. We constructed a modified version of the ASQ by pooling the questions from the checklists for 
children between 12 months and 60 months and eliminating questions assessing language development and questions which in our judgment required a linguistic prompt or response. The remaining questions were assigned to one of three age categories, based on the age by which children are expected to acquire the ability as listed in the ASQ manual. The early milestones were ones that we would expect typically developing children to pass prior to developing the linguistic skills assessed on the CDI-2 (11-21 months). The concurrent milestones were ones that typically emerge simultaneously with these linguistic abilities (21-36 months), while the late milestones would typically be achieved after these linguistic abilities developed (36-60 months). Answering the questions on the ASQ, requires fairly extensive knowledge of a child's abilities in a wide range of contexts, thus we did not send the modified ASQ to parents until their child had been in U.S. for three months.

Enrollment and Assessment Schedule

Because adopted preschoolers begin rapidly acquiring English immediately after adoption (Snedeker et al., 2007), all the preschoolers were enrolled in the study within a month after arriving in the U.S.. The families completed the first assessment between 1 week and 3 months after adoption $(\mathrm{M}=1.3$ months). For the adopted infants, our goal was to begin data collection when the child could produce between 5 and 20 words. Parents with eligible children between 12 and 16 months were encouraged to enroll. At first contact, the parents were asked if their child was producing 5 words yet. If they were, the parent was sent materials for the first session. If they were not, the parent was sent the MacArthur-Bates Communicative Development Inventory-1 (infant form) every month until the child produced 5 words, at which point they were sent the materials for the first session. 
The parents of adopted preschoolers were asked to participate every month for six months, with follow-up sessions three months and six months later for a total of eight sessions. The parents of infants were asked to participate every month for a year. This difference reflected our expectations about the pace of vocabulary development in the two populations. Our central questions focused on changes that happen as children acquire their first 400 words. On the basis of our earlier study, we expected that most of the preschoolers would acquire 400 words within the first six months of the study. In contrast, infants take about a year to move from a vocabulary of 20 words on the CDI-2 to a vocabulary of 400 words, thus we monitored them monthly throughout this period. Not all families completed every session on time. To be included in the longitudinal sample, families had to complete at least 6 sessions, spanning at least 9 months.

Each session consisted of a parental report of language development (CDI-2) and two videotaped speech samples (recorded approximately 2 weeks apart). Parents completed the background questionnaire on entering and exiting the study. The modified ASQ was sent every three months but only after the child had been with their adoptive family for at least three months. Thus the infants typically received it at sessions $1,4,7$ and 10 , while the preschoolers typically received it at sessions 3, 6 and 9 with some variation depending on when they enrolled.

\section{Results}

We began by testing the three working hypotheses on which this study rested. First, we have assumed that internationally-adopted children are rapidly immersed in an English language environment and have little access to bilingual informants. To confirm this we examined the parents' responses on the background questionnaire and verified this information by analyzing the speech samples that they provided. Second, we confirmed that the preschoolers were more 
cognitively mature than the infants by analyzing the parents' responses on the modified ASQ.

Finally, we demonstrated that the CDI-2 is a valid assessment of language development in internationally-adopted preschoolers by documenting parallel relations between the CDI-2 and transcript measures in both populations. These analyses are available in the supplementary materials posted online. ${ }^{3}$

\section{Description of CDI-2 data and the hierarchical analyses}

Table 2 summarizes the data that was collected using the CDI-2 parental reports of language development. To facilitate comparisons across the children we estimated the age at which each child had acquired 20 words in their productive vocabulary. This was defined as the age of language onset. For children who had an observation at which their total CDI-2 vocabulary was between 10 and 35 words, this session was used for the age of onset. Several of the preschoolers had larger vocabularies at their first session, for these children their age of arrival was used as their age of onset. This is a conservative solution, in the sense that any systematic error it introduces works counter to our hypothesis that the pace of acquisition is faster in preschoolers than in infants. Two infants had also passed 35 words by the time they participated in the first session. In both cases there was earlier infant questionnaire (CDI-1) with a production vocabulary between 10 and 35 words which was used to calculate the age of language onset. While many of the preschoolers had reached the ceiling of the CDI-2 vocabulary checklist by the end of the study, few of the infants did. Because only half of the infants had observations beyond 450 words, we focused our analysis on changes that occur before this point in typical language development.

\footnotetext{
${ }^{3}$ http://www.wjh.harvard.edu/ lds/pdfs/SGS-2010-Supplement.pdf
} 
Table 2

Our data contains multiple observations nested within participants and thus requires a statistical technique that models this internal structure, accounting for both variation within a participant and variation between participants. Hierarchical linear models provide a means for conducting regression analyses on data sets with two or more levels of structure. The hierarchical analyses were conducted in HLM-6 (Raudenbush, Bryk \& Congdon, 2005) using the HLM2 module. ${ }^{4}$

Our analytic strategy was largely guided by Singer and Willett (2003). For each analysis we began by constructing the unconditional means model. This is a model with no predictors which provides a baseline for assessing subsequent models. Next we explored the effects of the predictors that varied across sessions (level-one predictors). Our level-one predictors included: time since adoption, current age, age since language onset and current vocabulary size. Once the best level-one model was identified, we examined the effects of level-two predictors. Level-two predictors are factors that are stable across sessions in an individual participant, such as age of arrival or whether the participant was a part of the preschool or infant group. All models included an error term in each equation (the level-one equation and all level-two equations).

Models were compared in a stepwise fashion. If several factors could be added at a given step, then the factor that resulted in the smallest deviance statistic was added first. The more complex model was selected only if it resulted in a reliable decrease in the deviance statistic

\footnotetext{
${ }^{4}$ Each model was fit twice, once using the restricted maximum likelihood method, and once using the full maximum likelihood method. Parameter estimates and t-tests were taken from the model fitted with restricted maximum likelihood, while the deviance statistic and variance components were taken from the model fitted with full maximum likelihood (see discussion in Singer \& Willett, 2003). In all cases, the two methods of model fitting produced very similar results.
} 
(which was evaluated with a chi-squared test) and if the new parameter was reliably greater than zero (according to a t-test).

To facilitate informal comparisons between the models, we calculated the total variance in the level-one sample that could be accounted for by each model. To do this, we predicted the value of the outcome variable for each observation using the level-two parameter estimates produced by hierarchical model and conducted a simple regression of this value on the observed value. Singer and Willett (2003) call this measure $R_{y, y}^{2}$. By taking the value of $R_{y, y}^{2}$ for a model that includes a given effect and subtracting out the model that excludes this effect we can calculate the partial $R_{y, y}^{2}$ of the effect, or the proportion of the variance that it accounts for. This measure of effect size is directly comparable to the $R^{2}$ values used in simple regressions and allows us to compare level-one predictors with level-two predictors using the same scale.

For most analyses we only considered linear effects of the level-one predictors. Hierarchical models are based on the estimated level-one regression equations for each participant. In many analyses, some of the participants had only two or three data points in the relevant vocabulary range, making it difficult to rule out the linear model (or accurately estimate more complex functions). Fortunately, in typically-developing infants most of the effects of interest appear to be roughly linear, provided that one restricts the range of the analysis. For example, prior studies have found that the relation between noun proportion and vocabulary size has a quadratic component; initially it increases, then after about 200 words it declines (Bates et al., 1994). However, if we restrict the range to under 200 words (or over 200 words) the effect is approximately linear.

There is one exception to this. Prior research on vocabulary growth in typical infants has demonstrated that the pace of acquisition accelerates as more words are acquired, which is 
typically captured by a quadratic component in the growth model (see e.g., Ganger \& Brent, 2004; Fenson et al., 1994). For this reason we explored quadratic models in our comparison of vocabulary growth in preschool and infant adoptees. This analysis incorporated every session that each child contributed prior to reaching the ceiling of the CDI-2, thus there was sufficient data to estimate quadratic level-one models for each participant (5-12 sessions).

\section{Does the age of the learner affect the pace of vocabulary acquisition?}

For internationally-adopted children, there are three temporal dimensions that could be relevant to language development: the length of time that they have been in the U.S., their current age, and their age at the time of adoption. Our preliminary analyses demonstrated that these variables had quite different effects on word learning in the two age groups (see supplemental online materials). In the infants, vocabulary size was predicted by the child's age $\left(R_{y, y}^{2}=.44\right.$ ) and time in the U.S. and age of arrival did not account for substantial additional variance (partial $R_{y, y}^{2} \leq .02$ for both). In contrast, in the preschoolers, vocabulary size primarily depended on the amount of time that they had spent U.S. $\left(R_{y, y}^{2}=.60\right)$. Neither their current age nor their age of arrival predicted substantial additional variance (partial $R_{y, y}^{2} \leq .03$ for both).

It is not surprising that the most relevant measure of time is different for these populations. An infant who is adopted at 5 months of age, will acquire few words in the first six months, while a child who arrives at 15 months of age may begin speaking shortly after adoption. The preschoolers, in contrast, are ready to learn from the moment they walk off the plane, and so their vocabulary size is tightly linked to the amount of time that they have been in the U.S. To compare the pace of lexical development in the two populations, we need a way to equate these two time scales. 
Our solution was to align the children at an early point of language acquisition and then observe how rapidly they progressed from there. Language onset was defined as the point at which the child knew approximately 20 words. We calculated the time of each session relative to language onset and conducted a stepwise analysis of vocabulary size with age since onset as a level-one predictor and participant group (infant or preschooler) as a level-two predictor. To minimize the effects of ceiling-level performance on growth rates, we identified the first session in which the participant knew at least $90 \%$ of the words on the CDI-2 (612) and then removed all subsequent data points for that participant from the analysis. Six sessions were removed from four preschoolers and three sessions were removed from one infant.

\section{Table 3, Figure 1}

Table 3 describes the models fitted in this analysis. Because vocabulary growth accelerates in typical learners, we tested a quadratic model in addition to the linear one. Although, the quadratic model did not account for more level-one variance than the linear model, it did have a substantially lower deviance statistic, suggesting that there was a reliable quadratic component for some of the participants, but that the sign of this component was variable. In the remaining models, group $(1=$ preschooler, $0=$ infant $)$ was added as a predictor of the intercept, slope and acceleration in a stepwise fashion.

The model with the best fit includes group as a predictor of both slope and acceleration (partial $R_{y, y}^{2}=.09$ and partial $R_{y, y}^{2}=.04$, respectively). Specifically, older children initially learn at a much faster rate than infants ( 85 vs. 23 words per month). However, the rate of word learning gradually decelerates in preschoolers, suggesting either that the children are nearing the 
ceiling of the instrument or that the words which are acquired later present more challenges for them than the ones that are acquired earlier. In contrast the infant learners show acceleration with time, replicating the pattern observed in other longitudinal studies of early word learning. Figure 1 illustrates the vocabulary growth curves and the observed data points for both groups of adoptees in the longitudinal sample. These findings confirm our previous observation that adopted preschoolers learn more quickly than infants, suggesting a role for cognitive development (or prior linguistic experience) in the pace of language development.

\section{Do older learners show the same shifts in vocabulary composition?}

Next we explored the shifts in vocabulary composition that occur during early language development. The dependent variable in these analyses is the percentage of the words in the child's lexicon that belong to a particular category. For example, if the child knows 10 words and 3 are verbs then the verb percentage is $30 \%$. In each analysis vocabulary size was entered as a level-one predictor of vocabulary composition to explore whether these shifts occurred reliably across participants. Next, group was entered as a predictor of both the intercept and the slope (of vocabulary size) to explore whether there were any differences between the infants and preschoolers. To validate these effects within individual participants we took the first and last session that each participant contributed to the analysis, tallied the number of participants who conformed to the predicted pattern and conducted a sign-test.

Our first analyses explored two changes that occur in the initial stages of vocabulary development as children's lexicons grow from 0 to 200 words (Bates et al., 1994; Casadio et al., 1999). Many of the words that children learn first are social words (names, exclamations or verbal routines). The percentage of social words declines as the child develops a broader 
repertoire. Second, during this same time period the proportion of nouns grows, peaking at around 200 words.

\section{Table 4, Figure 2}

To explore whether these shifts occur in older and more cognitively mature learners, we selected all sessions with total CDI-2 vocabulary scores between 0 and 230 and analyzed them. ${ }^{5}$ Social Words were defined as all items in the CDI-2 categories games and routines, names and sound effects. As Figure 2 illustrates, both groups showed the expected profile: high but variable social word percentages at the beginning of acquisition, followed by a sharp decline. The models confirmed that there was a reliable (negative) relation between vocabulary size and the proportion of social words, which accounted for $58 \%$ of the variance. The two groups of adoptees did not differ in their initial preference for social words or in the magnitude of the subsequent drop, as evidenced by the lack of reliable effect of group on the intercept or slope (Table 4). The decline in social words was observed in all fourteen infants and all eight of the preschoolers who contributed at least two sessions to this analysis $(\mathrm{p}<.001, \mathrm{p}<.01$, respectively).

Nouns included all items in the categories: animals, toys, food and drink, clothing, body parts, small household objects, furniture, rooms and vehicles. As Figure 3a illustrates the proportion of nouns for both groups increased during this early phase of word learning and there were no differences between the groups in the intercept or slope of this function (Table 5). This increase accounted for $30 \%$ of the variance and was observed in all fourteen infants and seven of

\footnotetext{
${ }^{5}$ Many children who did not have a CDI-2 vocabulary observation between 150 and 200 words had one between 200 and 230. Thus expanding the range helped ensure more robust level 1 models.
} 
the eight preschoolers who contributed at least two sessions to this analysis $(\mathrm{p}<.001, \mathrm{p}=.07$, respectively).

Our next analysis explored the gradual drop in noun proportion that occurs after 200 words. When children are near the ceiling of the CDI-2, vocabulary composition necessarily reflects the composition of the checklist. To ensure this did not unduly influence our findings, we removed observations where children had acquired over $90 \%$ of words from these analyses. Thus vocabulary size in this sample ranged from 200 to 612 words. In our statistical analysis we subtracted 200 words from the child's total vocabulary so that the intercept of our model would reflect the proportion of nouns in the child's lexicon at the beginning of this period (Table 6). The results confirm that there is a substantial drop in the noun proportion as vocabulary rises (accounting for $38 \%$ of the variance). There are no reliable group differences between the infants and preschoolers (see Figure 3b). The decline in nouns was observed in eleven of the twelve infants who contributed to the analysis and all nine of the preschoolers $(p<.01, p<.005$, respectively).

Table 5, Figure 3, Table 6 (in that order)

This decline in nouns is brought on by an increase in other word types. For example, between 0 and 400 words many children begin to produce more predicates, such as verbs and adjectives. Verbs may be difficult for early learners to acquire because they are syntactically complex words and their meanings and referents are often tightly linked to the arguments that they take (see Gleitman, 1990; Gentner \& Boroditsky, 2001, for reviews). Many verbs refer to events that are short in duration and thus may not be going on at the time the word is spoken. In 
contrast, adjectives are typically less syntactically complex and often refer to properties that are relatively stable. Thus we chose to analyze verbs and adjectives separately. We also examined a third class of words (time words) which are abstract and late to develop in typical infants.

The verbs conformed to the pattern seen in previous studies of typically-developing infants. As vocabulary size grew, the proportion of the child's words that were verbs increased (see Figure 4). This effect accounted for $56 \%$ of the variance, and there were no differences between the groups (Table 7). An increase in the proportion of verbs was observed in all fourteen infants and eight of the nine of the preschoolers $(\mathrm{p}<.001, \mathrm{p}<.05$, respectively).

The adjectives, however, patterned differently (Table 8, Figure 5). In both groups, the proportion of adjectives increased as vocabulary grew, as we expected. This increase was somewhat more variable across participants appearing in twelve of the fourteen infants and seven of the nine of the preschoolers ( $\mathrm{p}<.05, \mathrm{p}>.1$, respectively). But critically, there was also a main effect of group (present in the model as an effect of group on the intercept); older children knew more adjectives than infant learners.

Table 7, Figure 4, Table 8, Figure 5

To explore the source of this effect, the adjectives were split into three classes. The first consisted of 20 adjectives describing behavior or a person's internal states. This class included: words for physiological states (tired, hungry), words for mental states (scared), evaluative adjectives (good, naughty), and adjectives that are often used as behavioral directives (be careful, be quiet). Many of these words are abstract in the sense that they do not describe properties that are typically visible. However, they are of great social and practical importance because they 
allow adults to determine the child's needs and verbally regulate the child's behavior. The second class, color words $(\mathrm{N}=8)$ which refer to a concrete perceptual property that is not typically critical for social interaction. However, these words are often the focus of explicit parental teaching. The third class included the remainder of the adjectives on the checklist $(\mathrm{N}=35)$, words which are primarily used to describe things (big, pretty, wet).

The goal of these analyses was to understand which adjectives were learned when, rather than to determine the proportional representation of different classes of words in the child's lexicon. Thus our dependent measure was the percentage of adjectives, of a given type, that the child knew. For example a child who knew four of the eight color words would be credited with $50 \%$, no matter how large his vocabulary was. These values will inevitably rise as vocabulary increases. The question of interest is whether they rise faster for preschoolers than for infants. The results of these analyses are summarized in Table 9 and Figure 6 . The behavioral adjectives appear to be the primary source of the preschoolers' precocious adjective use. In the model with the best fit, there is a significant interaction between vocabulary size and group (modeled as an effect of group on the slope). Preschoolers learn behavioral adjectives at almost twice the rate of infants. Color words in contrast are learned quickly by both infants and preschoolers and there are no reliable differences between the two groups. For the other descriptors there is a small but reliable main effect of group. At any given vocabulary level, preschoolers know one or two more of these words than infants. Additional analyses on subgroups of the descriptors (e.g., size vs. other properties, positive valence vs. negative valence) failed to reveal any further differences between them. 


\section{Table 9, Figure 6}

Our next analysis focused on words for time. These are a syntactically diverse set of words including some nouns, adverbs and prepositions, which develop relatively late in first language acquisition and are notoriously abstract. While several children had acquired one or two time words early on (resulting in high proportion of time words in the early sessions), the children as a whole showed a significant increase in the proportion of time words as vocabulary size increased (Table 10, Figure 7). This effect was quite variable across participants appearing in eleven of the fourteen infants and only five of the nine of the preschoolers $(p<.1, p>.3$ respectively). There was a reliable main effect of participant group - the preschoolers had a larger proportion of time words in their vocabularies than the infants.

We divided these words into two classes. The first contained four words that can be readily used to describe the present (morning, night, day, and now). These are examples of what Nelson (1996) called natural time: temporal concepts that she argues are directly experienced and independent of culture. The second class consisted of words that are used most naturally to refer to events in the future or past (after, before, later, tomorrow, tonight, yesterday and today).

Nelson has argued that these temporal notions must be abstracted from experience and constructed, making it more difficult to transform them into concepts that could be linguistically encoded. We reasoned that if preschooler's precocious use of time terms is driven either by a better understanding of time or a more robust ability to think about events occurring at different times, then this should be particularly helpful in learning the terms for the future/past. 
Again for each session, we calculated the percentage of words in each class that the child knew (Figure 8). Older children showed a robust advantage for the future/past terms (Table 11). The slope of their learning curve was 4 times as great as that of the infants, who acquired very few of these words. At 400 words only four of the fourteen infants had learned one of the future or past terms, while eight of the nine preschoolers had (with an average of two terms per child). In contrast, the words for the present were relatively easy for both groups, seven of the infants and six of the preschoolers produced one of these terms before reaching a vocabulary of 200 words.

Table 10, Figure 7, Table 11, Figure 8

Thus we found both parallels and differences in the words that the older and younger children produced. All children began word learning with a rich set of social words. As vocabulary size grew to 200 words, the proportion of social words declined and more nouns began to emerge. This was followed by a period of growth for verbs and adjectives in both groups. However, there were fine-grained differences between the two groups which suggest ways in which cognitive and social development might influence language acquisition. The adopted preschoolers learned more adjectives than the infants. This advantage appeared to mostly stem from greater knowledge of adjectives that might be applied to their own behavior or internal states. They also acquired words for future and past events substantially earlier than the infant learners. 


\section{Do older learners have a one-word stage?}

The final goal of this study was to explore the emergence of combinatorial speech in older learners. In infant learners, word combinations begin appearing when children know about 50 to 100 words and become a robust feature of children's speech at a vocabulary size of around 200 to 300 words (Fenson et al., 1994). On the CDI-2 parents are asked to indicate whether their child is producing multi-word utterances never, sometimes or often. Table 2 lists the parent's response to this question at the first and last session. In both the infant and preschool samples, most of the children were producing no combinations at the outset of the study but were producing combinations "often" when the study ended approximately one year later. Thus we confirmed that a one-word stage is present in at least most adopted preschoolers.

Bates and her colleagues noted that the point at which children are reported to "often" produce word combinations appears to be a more stable measure than the point at which they "sometimes" do (Bates et al., 1995). In our sample many parents would check "sometimes" on one session and then revert back to "never" on the next session. If we use this more stringent standard for producing combinations, all of the children except for one preschooler (Child I) were observed during the one-word stage. This family was unable to collect the first data set until three months after adoption, at which point the child knew 159 words. Four of the other eight children who had gone through a one-word stage were reported to "often" produce combinations by 3 months. Thus it is possible that Child I had passed through a one-word stage before data collection began.

Figure 9 
Two of the preschoolers (Child B and Child E) were reported to be producing combinations "sometimes" in the first parental report. In both cases, data collection began during their first month in the U.S. when their vocabularies were quite small. To determine whether these children went through a one-word stage in their acquisition of English, we examined the two videotaped speech samples that were returned with the first CDI-2. In their first sample, both children produced one-word utterances in English and multiword utterances in their native language. However, neither child produced a multiword utterance in English that was clearly combinatorial. ${ }^{6}$ For both children, simple combinations began to emerge in their second session, about two weeks later (e.g., "daddy please" "Sandy's school"). Thus both children appear to be breaking into multiword speech during the period in which the first CDI-2 was filled out. In contrast, Child I, whose first speech sample occurred at 3 months, was already producing clear multiword utterances at that time (e.g., "I want dinosaur" and "This a big one").

Next, we examined whether the transition to multiword speech happened at the same point relative to vocabulary development in each group. We estimated the child's vocabulary size at the point at which they began "sometimes" producing combinations and at the point at which they began "often" producing combinations. This was done by averaging the child's vocabulary size on the session before the benchmark was reached with their vocabulary size on the session in which it was first reported. There were no differences between the groups on either measure $[\mathrm{t}(15)=.19, \mathrm{p}>.5, \mathrm{t}(19)=.57, \mathrm{p}>.5$, for "sometimes" and "often" respectively]. As Figure 9 illustrates both the infants and the preschoolers began occasionally producing combinations at around 80 words and began producing them regularly at about 230 words. These numbers closely match the prior findings for typically-developing infants (Bates et al., 1995).

\footnotetext{
${ }^{6}$ Child E uses the phrases "this one" and "thank you". However he does not use any of these words in other contexts. Child B produces count sequences several times suggesting that she has the articulatory wherewithal to produce longer chunks, but she never combines these numbers with other words.
} 


\section{Discussion}

The present study tracked the acquisition of English for one year in a small group of internationally-adopted preschoolers and infants. Both groups of children started off using single-word utterances. In both groups, early vocabularies were dominated by social words (routines, names and sound effects). Initially the proportion of nouns grew rapidly but then dropped after children had acquired about 200 words. In contrast the proportion of verbs and adjectives increased as vocabulary expanded. In both groups of children, the onset of word combinations was closely linked to vocabulary development, with the first combinations appearing around 80 words and combinations becoming frequent at around 200 words. Taken with our earlier study, these results demonstrate that many of the qualitative shifts that characterize early language production are not driven solely by cognitive development or maturation. They occur even in children who are acquiring English at the ripe old age of three or four. Thus our findings support contingent-acquisition theories which attribute the onset of combinatorial speech and shifts in early lexical composition to properties which are intrinsic to the process of language acquisition. ${ }^{7}$

These findings go beyond our previous work in six ways. First, by using a truly longitudinal design we were able to confirm that the observed shifts characterized the language development of individual children. Our prior findings largely depended on comparisons across children who had different levels of linguistic knowledge at the time of data collection. Consequently, the correlations between vocabulary size and vocabulary composition could have reflected individual differences in ability and tactics (e.g., perhaps smarter children both have larger vocabularies and are more likely to acquire verbs and closed-class items). In the present

\footnotetext{
${ }^{7}$ Presumably these properties are only intrinsic to the process of language acquisition as it is carried out by young children. Adult learners, who can rely on bilingual informants, texts and a greater capacity for metalinguistic reasoning, seem to follow a very different path (Clahsen, 1990).
} 
experiment we found that the critical shifts in vocabulary composition occurred for over $85 \%$ of the children in each group, demonstrating that these are robust patterns that characterize development on an individual level.

Second, by using internationally-adopted infants as our comparison group, rather than nonadopted infants, we controlled for several factors that were confounded with age in the previous study, providing us with a cleaner manipulation of developmental status and making any differences that we find between the two groups more interpretable. Like the internationallyadopted preschoolers, these infants are drawn from a population of children who were put up for adoption, thus they are likely to have experienced many of the same early biological risk factors. In addition, both the adopted infants and preschoolers are being raised by families that chose to adopt children and met the financial and personal criteria imposed by the adoption system. The parents had similar levels of education and were likely to have had parallel motivations for participating in our study. Of course, the two groups of children necessarily differ in several respects: the preschoolers spent longer in an orphanage, learned more of their native language and had been adopted more recently when the study began. We will return to these issues when we discuss the differences that we observed in the language development of the two groups.

Third, we provided support for the working hypotheses that motivate this work (see the supplemental online materials). Our analyses of the children's speech samples confirmed that internationally-adopted preschoolers quickly stop speaking their native language and begin using English. We also verified that the adoptive parents are primarily using English to communicate with their children. Even in the earliest sessions (just weeks after arrival), over $90 \%$ of the parental utterances were solely in English. By the end of the study, the parents reported that their children appeared to know only a few words of their native language and rarely used them. 
These patterns are consistent with our working hypothesis that adopted children learn their new language through daily interactions with their caregivers, much like infants do, with little continued access to their native language or bilingual informants. Our developmental questionnaire (the modified ASQ) provided support for the critical conjecture that adopted preschoolers are more cognitively mature than infant language learners. We compared performance on the ASQ in the preschoolers and infants in the third month and tenth month of the study. At the first assessment, the adopted preschoolers had already mastered most of the gross-motor, fine-motor, problem solving and social skills that typically coincide with early language development and they were making substantial progress on the milestones that characterize development in the preschool years. The adopted infants, in contrast, had mastered less than half of the concurrent milestones and (unsurprisingly) had passed few of the preschool milestones. In fact, the ASQ scores for the preschoolers at the beginning of the study were considerably higher than the scores for the infants at the end of the study. This suggests that adopted preschoolers should already possess the possible cognitive prerequisites to the linguistic skills that are measured by the CDI-2.

Fourth, our longitudinal design allowed us to conduct precise comparisons of the pace of language acquisition in older and younger learners. Our prior work suggested that older children acquired words at a more rapid rate, reaching the ceiling of the CDI-2 within the first year after arrival. However, a more precise comparison was hampered by the lack of a comparable longitudinal data set for infant learners.. In the present study we began collecting data from both infants and preschoolers at an early point in language development (a vocabulary size of 20 words) and then tracked the pace of acquisition from this point forward. We found that the initial pace of word learning was almost four times as fast in the preschoolers as it was in the 
infants. In the infants, there was a gradual acceleration in the rate at which new words were acquired, echoing prior findings on early lexical development. The preschoolers, however, showed a slight deceleration in the pace of word learning. This raises two issues which we will return to: Why do preschoolers learn words more rapidly than infants and why does their CDI vocabulary growth slow down over time?

Fifth, by catching children at the earliest phases of language production, we were able to explore phenomena that largely eluded us in our prior study. We found that like young infants, internationally-adopted preschoolers begin with a vocabulary that is largely populated by proper names, social routines and sound effects. As vocabulary size grows, social words decline as a proportion of the total and common nouns increase. Critically, we were able to observe the transition from one-word utterances to early word combinations in eight of the nine preschoolers (and all of the infants). Thus we can conclude that a one-word stage occurs in maturationallyadvanced learners and is not simply a side effect of the cognitive limitations of infancy. Furthermore, the systematic relation between vocabulary size and combinatorial speech that has been observed in infants was also present in older children, suggesting that it reflects a robust feature of the process of language acquisition.

Sixth, we investigated two facets of children's lexical development that we had not explored before (the acquisition of adjectives and time words) and found surprising differences between the older and younger learners. In both preschoolers and infants, adjectives and time words increased proportionally as vocabulary grew from 0 to 400 words. However, the preschoolers learned more of these words at an earlier stage in lexical development. In the case of the adjectives, this was primarily attributable to the precocious acquisition of words that are used to direct children's behavior or describe a person's internal state. The preschoolers' precocity with 
temporal terms was driven by the early acquisition of words that are typically used to refer to events in the past and future (e.g., later, yesterday and tomorrow).

The rapid use of abstract adjectives and temporal terms in older adoptees raises the possibility that acquisition of these words in younger children is hampered by cognitive immaturity. We explore this issue in more detail below. But critically these effects also provide a concrete demonstration that our methods are sensitive to subtle effects of age on qualitative features of early language acquisition. Adjectives and time words are represented by small numbers of items on the CDI-2 (12 and 65 words respectively), thus these measures are noisier than those for larger lexical classes such as nouns and verbs. Yet our analyses had the sensitivity to reveal differences between the age groups. In addition, the differentiation that we see across lexical classes confirms that the parental report provides multiple distinct indices of vocabulary development. For example, we saw age group differences for the adjectives but not the verbs, even though these two lexical classes typically develop in tandem.

In the remainder of this discussion, we examine the theoretical implications of our findings focusing on five issues: 1) possible explanations for the precocious acquisition of temporal words and abstract adjectives in older children; 2) what the differences in vocabulary growth rates tell us about the role of maturation in vocabulary development; 3) how our data bear on theories of vocabulary acquisition; 4) the constraints this data places on our understanding of the one-word stage; and 5) the limitations of the present study and the degree they limit the conclusions that we can draw. 


\section{On time and internal states}

Perhaps our most surprising finding was the differences that we found between the preschoolers and the infants in the acquisition of adjectives and temporal terms. In both cases the older children were more successful in learning precisely those words that appear later in typical infants. Adjectives for behavior and internal states were late to develop in the infants but appeared fairly early in the adopted preschoolers. In contrast, color words emerged very early in development in both groups with no differences between the two. Similarly, time words for past and future events were slow to emerge in both groups but were learned more readily by the older children, while time words that are often used in the present (night, day, morning) appeared much earlier and showed no group differences.

There are several possible explanations for the group differences. First, infants may have difficulty representing the very concepts that are encoded in these terms. For example, in the case of internal and behavioral adjectives, young learners might have limited abilities to reflect on these states (in themselves or in others), making it difficult for them to learn the words that encode them. Alternately, the development of general cognitive skills could facilitate the acquisition of these terms in older children. For example, infants might have difficulty remembering the events in the past that are being referred to or predicting the future events that are under discussion, limiting their ability to learn the meanings of temporal terms. Similarly infants may have more difficulty then older children in inferring when internal states are under discussion, even if they can represent these states.

Another possibility is that learning words for these tricky concepts in one language, aids the child in acquiring these words in their second language. The limited evidence that we have suggests that the preschoolers in this study had made substantial progress in acquiring their birth 
language prior to adoption. While most were said to have mild to moderate language delays, they were also reported to use sentences of at least four to five words. This is consistent with studies on the cognitive development of children in Russian orphanages, which find systematic but moderate delays, equivalent to about $25 \%$ of the child's chronological age (Sloutsky, 1997; The St. Petersburg-USA Orphanage Research Team, 2005). In typically developing infants these abstract time words and adjectives are generally produced by around 30 months of age (Dale \& Fenson, 1996). Thus it is certainly plausible that many of our preschool adoptees had learned the translation equivalents of some of these words in their birth language prior to adoption.

It is also possible that older children could have social goals and motivations that lead them to seek out words that encode these particular concepts, or that parents might have expectations of older children which lead them to use these words more often in conversation. The temporal terms for future and past events are words that are often used in discussing the postponement or scheduling of events, a common area of dispute between parents and young children (you can watch more T.V. tomorrow, we are going to eat the ice cream after dinner). The behavioral and internal adjectives might also be more relevant to an older child who has more experience fulfilling her needs and regulating her actions. While it is reasonable to ask a preschooler if she is hungry or tired, parents of young toddlers are more likely to rely on behavioral cues.

We cannot disentangle these hypotheses with the data that we have. To tease apart cognitive and linguistic factors we would have to manipulate the child's age independent of their level of experience with the birth language, an impossibility in our population. Distinguishing motivational and cognitive factors may not be possible in any population: what is motivating is 
likely to depend in part on the cognitive system of the agent. Similarly, parental input is likely to be shaped by the interests and apparent comprehension of the child.

An alternate approach is to explore each hypothesis from the perspective of typical development. For example, an increase in input frequency is only a plausible explanation for older children's success in acquiring abstract temporal terms, if we believe that young infants lack sufficient exposure to these words. But corpus analyses have documented that temporal terms for future or past events are ubiquitous in conversations with young toddlers (Sachs, 1983; Lucariello \& Nelson, 1987; Levy \& Nelson, 1994). Infants' slow acquisition of past and future temporal terms appears to reflect a difficulty in grasping their meanings rather than a limitation in the input or motivation. Children begin talking about the past and future long before they master temporal terms, suggesting that they are motivated to express these relations (Nelson, 1996). In fact young toddlers often produce past and future temporal terms in appropriate discourse contexts before they fully understand what they mean (Levy \& Nelson, 1994; Tare \& Shatz, 2005). These early uses respect the distributional constraints of the terms but may violate their meanings (e.g., tomorrow being used for yesterday, or before for after). This is precisely what we would expect to see if infants were able to extract temporal terms from fluent speech and identify their domain of reference, but were unable to ascertain their precise meanings (see Tare, Shatz \& Gilbertson, 2008). This line of reasoning suggests that preschool adoptees may use more temporal terms early on because they are more successful in determining their meanings. This could result from: better access to concepts that have previously been lexicalized, improvements in memory which make it easier for children to hold the relevant events in mind (and thus ascertain their relation), or conceptual/maturational changes that alter the range of concepts that are available for word learning (or their relative salience). 


\section{Accounting for the differences in the pace of lexical acquisition}

While the infants initially learned words slowly, the adopted preschoolers hit the ground running, acquiring an average of 85 words in the first month after arrival. Despite this increase in speed, the content of early lexical development was largely unchanged (with the two exceptions noted above). The proportion of nouns initially increased but then declined after 200 words, while the proportions of verbs, adjectives and time words increased as vocabulary size grew. Thus the preschoolers went through the same stages as the infants but they did so more quickly. The uniformity of this acceleration is inconsistent with developmental hypotheses that posit a qualitative shift in the kind of words that children can learn. For example, if this speeded pace was attributable to the development of new abilities to learn relational terms then we would expect to see more verbs in the initial vocabularies of the preschool adoptees.

One possibility is that this speeded up acquisition trajectory reflects the development of domain-general processes affecting learning rate. Older children might require fewer exposures to link a word and concept, or they might be more likely to encode the input or better able to retain it. Development of this kind could play a role in the acceleration in word learning that is typically observed during the second and third years of life. Alternatively, the difference in learning rate between the preschoolers and infants could reflect improvements in lexical processing that are attributable to the older children's prior experience acquiring a natural language and producing words.

A more puzzling question is why vocabulary growth appears to decelerate in preschoolers. It is unlikely that these children became less effective word learners as they acquired more words. There are three more plausible explanations for this finding. First, this deceleration could simply be an artifact created by the ceiling of our instrument. To minimize this possibility we removed 
all sessions that occurred after the child had acquired $90 \%$ of the words on the CDI-2. However, given the speed with which the children were learning English, this may not have eliminated the ceiling effect. Second, deceleration could occur because the words that children are learning at higher vocabulary levels are, in some objective sense, more difficult and thus take longer given a learner with constant abilities. A third possibility is suggested by research comparing the CDI-2 checklist with diary studies (Robinson \& Mervis, 1999) or speech samples (Hart, 2004). When children's vocabularies are small the CDI appears to capture almost all of the words that they know. However, as vocabulary size grows, the proportion of the child's vocabulary that is on the checklist shrinks. For example, Robinson and Mervis found that the checklist captured fewer than $50 \%$ of the words that their participant had used when his CDI-2 vocabulary was at 500 words. Consequently, if the CDI-2 vocabulary growth function was linear, then rescaling it to predict the total vocabulary growth would reveal acceleration over time. While we do not know how variable this function is across children, the Robinson and Mervis data suggests that this hidden acceleration is more than an order of magnitude greater than the deceleration in CDI-2 vocabulary that we observed in our preschool sample. Thus there is no reason to assume that vocabulary growth is actually slowing in this population. Notice that this data also has implications for interpreting the infant growth curves. Like prior longitudinal studies using the CDI-2, we found a modest acceleration in vocabulary growth over time, but because the CDI-2 samples a smaller proportion of the child's lexicon at larger vocabulary sizes, the true rate of acceleration is likely to be much greater.

\section{Implications for theories of lexical development}

The present study demonstrated that the broad shifts that characterize early vocabulary development persist in older learners. This finding is clearly inconsistent with any account that 
attributes these shifts to the availability of new concepts or to domain-general cognitive development. In contrast it supports theories which attribute changes in vocabulary composition to contingencies in the process of acquisition itself.

Critically, these results are fully compatible with the syntactic bootstrapping hypothesis (Gleitman, 1990) which posits that vocabulary composition is largely shaped by the child's access to information which will allow her to infer the meaning of the word. Novice learners cannot understand the utterance in which the word appears and are forced to rely on situational cues which allow them to learn many nouns, but few verbs. But as the learner gains linguistic knowledge, she is able to create increasingly sophisticated representations of linguistic context which support the acquisition of increasingly abstract words (Gillette et al., 1999; Snedeker \& Gleitman, 2004; Gleitman et al., 2005). On this hypothesis the mechanism of change remains the same regardless of the age of the learner, predicting the strong similarities that we observed between infants and preschool learners.

For over twenty years, research on early vocabulary composition has largely centered on Gentner's noun-dominance hypothesis (1982). Thus it is reasonable to ask how this work bears on that proposal. We chose not to frame the study in this way, primarily because we believe that the noun-dominance hypothesis lives a dual life. Many readers have interpreted it as a cognitive/maturational hypothesis (see e.g., Hoff, 2001). On this construal nouns are acquired before verbs because the concepts that they encode are available at an earlier stage in development. Our results clearly speak to this interpretation of the noun-dominance hypothesis. Preschool-aged children with prior linguistic experience have presumably developed the concepts encoded by the verbs that are typically learned by toddlers. Yet they go through the 
same shifts in vocabulary composition, suggesting that there is no need to invoke cognitive change to explain this phenomenon in first language learners.

In subsequent writings, however, Gentner herself has explicitly rejected this cognitive/maturational account and has argued instead that the shift in vocabulary composition is caused by the child's growing knowledge of the language-specific conflation patterns that organize verb meanings (Gentner \& Boroditsy, 2001). This is clearly a contingent-acquisition hypothesis, since the cause of the change is the child's growing knowledge of her language and not changes in her general cognitive abilities. But it is not clear what predictions this hypothesis makes for second-language acquisition in childhood.

If children simply attempt to map second-language labels onto the conceptual conflations provided in their first language, then we would expect to see precocious verb learning to the degree that verb semantics in the two languages are aligned. From a typological perspective the verb lexicalization patterns of English, Russian and Chinese are quite similar (Talmy, 2000). All three are considered satellite-framed languages, a distinction with far reaching effects on the division of labor between verbs and grammatical morphemes. In fact many of the most common verbs in child-directed speech in English have direct translation equivalents that are among the most common verbs in Mandarin child-directed speech (Snedeker, Li \& Yuan, 2003). Nevertheless, we have found no evidence that children from China, or Russia, learn verbs at an earlier stage than monolingual infants. ${ }^{8}$

On the other hand, if child learners attempt to map second-language labels directly to prelinguistic representations of event components, then the noun-dominance hypothesis would

\footnotetext{
${ }^{8}$ There were only two preschoolers from China in the present sample. However, in our previous cross-sectional sample which consisted of 25 children from China (Snedeker et al., 2007), we also found no evidence of precocious verb acquisition. We have not investigated the degree to which early English verbs have direct translation equivalents in Russian.
} 
predict that second-language verb learning, like first-language verb learning, would initially be slow and effortful, accelerating as the child learns more about the language and its conflation patterns. The current data is consistent with this reading of noun-dominance hypothesis as well as Gleitman's informational change hypothesis (but see Havasi \& Snedeker, 2004).

\section{Why is there a one-word stage?}

Our dense longitudinal data set provided clear evidence that most, if not all, older adoptees go through a short stage in which they primarily produce single word utterances. This cannot be accounted for by limitations in their motor skills, memories or articulatory abilities; these children were reported to produce 4-5 word utterances in their birth languages. The transition to combinatorial speech was closely linked to vocabulary size. Both preschoolers and infants produced occasional combinations after acquiring about 50-100 words and produced frequent combinations at about 150-300 words. This suggests that the connection between lexical development and combinatorial speech is not simply a side effect of some general maturational time table (like the correlation between first words and first steps). Instead it reflects more systematic connections between the two processes.

Obviously the present study cannot tell us what those connections are. Two constraints should shape our hypotheses. First, this correlation is one between producing words and producing combinations. There is ample evidence that children interpret sequences of words many months before they produce them (Golinkoff et al., 1985; Gertner, Fisher \& Eisengart, 2006). Receptive word knowledge is unlikely to play a critical role in this correlation, since comprehension vocabulary is not strongly correlated with production vocabulary (Bates et al., 1995).. Second, this correlation is not a necessary consequence of the content of children's early lexicons. Early word combinations often involve two words that the child has been using 
separately for many months like hi dad or my cookie (Bloom, 1973). One possibility is that children need to gain sufficient practice retrieving a variety of words during production before they gain sufficient skills to grab two of them quickly enough to produce them in a single intonational phrase.

\section{Limitations of the present study}

There are two clear limitations to the present study. First, like all natural experiments our comparison between older and younger learners is complicated by other differences between the two populations. In the present study we equated the two groups to the greatest degree possible by comparing internationally-adopted preschoolers with internationally-adopted infants. Nevertheless the older and younger children differed in several respects. Not only were the infants younger but they also had had less exposure to their birth language and had spent less time in institutional care and thus would be expected to have less pronounced cognitive delays (Miller \& Hendrie, 2001).

Our analyses of the ASQ scores ruled out the possibility that global cognitive delays in the preschoolers were substantial enough to jeopardize our manipulation of maturational age. On every dimension we measured, the preschool adoptees were more cognitively sophisticated than the infants who were at similar point in vocabulary development. Thus the parallels that we find between the early language development in older and younger learners are unlikely to be due to a common set of cognitive changes in both groups.

More problematic for this line of work is the possibility that the development of children from orphanages might be divergent, rather than merely delayed. Institutional environments can have lasting effects on qualitative features of children's emotional development and social cognition (Fries \& Pollak, 2004; Yagmurlu, Berument \& Celimli, 2005; Camras, Perlman, Fries 
$\&$ Pollak, 2006). Presumably this experience might also alter the course of cognitive or linguistic development. If these effects are greater for children adopted at older ages then they are a confound in the design of our natural experiment.

Note that, while confounds like this hinder our ability to interpret differences between the populations, they have little effect our ability to interpret similarities. For example, we cannot conclusively determine whether the faster pace of early language development in the adopted preschoolers is attributable to their relative cognitive maturity, their prior experience with language, or their prolonged experience in the orphanage (though the later hypothesis seems implausible). However, these confounds do not undermine our claims that vocabulary composition and the presence of a one-word stage reflect contingencies in the process of language learning. Where we find no differences between the preschool and infant learners we can conclude either that none of the three factors affect that feature of acquisition, or that two or more of the factors do so but they just happen to cancel each other out. Parsimony and probability favor the former explanation.

Concerns about these other differences are further mitigated by looking more closely at the effects that we would expect each of them to have. While we know of no concrete proposal about how institutionalization might affect subsequent language acquisition, one plausible hypothesis is that institutionally-raised children would be less sensitive to social-pragmatic cues to word meaning, such as eye-gaze or pointing. Since these cues typically highlight locations in space and the objects that occupy them we might predict that institutionalization would initially hinder noun learning, resulting in a more balanced early vocabulary, and slowing down the pace of early acquisition. We see no sign of this in our data set. 
Similarly, while prior linguistic experience could account for the rapid pace of word learning in the internationally-adopted preschoolers, it seems unlikely that it could mask the effects of cognitive maturation on vocabulary composition or sentence complexity. In fact, we would expect that heavy reliance on prior linguistic experience would, like maturation or cognitive development, eliminate some of the characteristic patterns of early language acquisition. For example, if shifts in vocabulary composition depend upon acquisition-induced insights about the kinds of ontological categories that can be lexicalized, then we would expect internationallyadopted preschoolers to have precociously diverse lexicons.

The second limitation of this study is the small size of our sample. Our dense longitudinal design allowed us to closely track lexical development in individual children, however it limited our sample size because of the demands that it made on the parents and on our resources. Hierarchical models do not lend themselves to conventional power analyses. However, close examination of the results suggests that these analyses were capable of detecting fairly small effects. First, several of the differences that we did find between the preschoolers and infants were modest in size. For example, the effect of participant group on the adjective proportion accounted for just $6.4 \%$ of the variance, while the deceleration of vocabulary growth in the older adoptees accounted for only $4.3 \%$ of the variance. Second, we can hazard a guess about the possible magnitude of the effects of participant group by comparing the $R_{y, y}^{2}$ values for models which contained these predictors, to the $R_{y, y}^{2}$ values for models without them. For social words, nouns and verbs these nonsignificant effects were quite small, accounting for between $0.1 \%$ and $2.3 \%$ of variance. In contrast the effect of vocabulary size in these analyses accounted for between $29.6 \%$ and $58.4 \%$ of the variance. While we cannot conclude that there are no 
differences between our older and younger children on these dimensions, we can conclude that any differences that exist are considerably smaller than the effects of vocabulary size.

More caution is warranted in generalizing from this sample to the broader population of internationally-adopted children. Because our sample is both small and self selected it is unlikely to reflect the full range of variation. There could be some subgroup of adopted preschoolers that have a different acquisition trajectory than the one documented here. For example, older preschoolers or children who are more metalinguistically savvy may use different learning strategies and thus might begin acquisition with a more diverse lexicon. There was considerable variation in developmental rate and vocabulary composition in both groups, but with the present small sample we cannot determine the correlates of this variation. These concerns are mitigated by several considerations. First, as we noted in the results section, the critical patterns were present in all or almost all of the older children, suggesting that they are widespread. Next, many of the patterns that we observed here were also documented in our prior study in which families only agreed to participate in a single session (Snedeker et al., 2007), suggesting that they persist over changes in selection pressures. Finally, the pattern of drop out in the sample suggests that the selection demands of the longitudinal study had similar effects in both populations: $60 \%$ of the preschoolers who began the study completed it and $67 \%$ of the infants did. Additional analyses were conducted on the full sample (including the children who dropped out) and the results confirmed those reported here.

\section{Final Words}

The present study demonstrates that several critical features of early language development are present in older learners. Like young infants, preschoolers who are learning a new language through immersion in the home go through a one-word stage before they begin producing 
combinatorial speech. Like infants, their vocabulary is initially dominated by social words and then nouns. Thus these features appear to reflect contingent properties of language acquisition, rather than the maturation of language specific abilities or broad cognitive changes in the learner. Other features of acquisition however vary with the maturational status of the learner. Older children were quicker to learn temporal terms that situate events in the past or future and adjectives for behavior and internal states, suggesting that cognitive development or experience with a language may play a critical role in the acquisition of these words.

While our findings have been primarily focused on vocabulary acquisition, they may have implications for the role of maturation in other facets of language development. Lexical representations link together the phonological form of a word with its semantic content and syntactic features. Thus the process of word learning constrains other aspects of language development and is constrained by them in turn. To date we have not examined phonological acquisition in this population. Given the rapid onset of word production in these children, it is likely that phonological acquisition and lexical learning are occurring simultaneously. Our analysis of the transition to combinatorial speech (in the present paper) and our analysis of syntactic complexity (in Snedeker et al., 2007) provide a preliminary glimpse into the relation between word learning and syntactic production. Both analyses find that internationallyadopted preschoolers show the same systematic connection between utterance complexity and vocabulary acquisition as typically-developing infants (Bates \& Goodman, 1997). Thus it appears that these aspects of syntactic acquisition are not primarily governed by maturation or cognitive development.

Nevertheless, the present data leave open the possibility that maturation plays a role in other aspects of syntactic or phonological development. For example, nothing in our data speaks to 
the question of whether the onset of mandatory tense marking is driven by maturation (Wexler, 1999). In fact, the population differences that we observed for time words and behavioral adjectives highlight the importance of testing specific developmental hypothesis about particular phenomena. We cannot assume that there will be just one answer to the question of whether (or how) cognitive development influences language acquisition. 


\section{Authors Note}

We thank all the families who participated for the enormous amount of effort that they put into this project. We are grateful to Katie Felkins for her analysis of language use in the transcripts and for her tireless assistance. We also thank Nadia Chernyak, Abbie Claflin, Ellen Godena, Candice Ishikawa, Corinne Jones, Eva Liggett, Angela Lou, John Ste Marie, Cathy Tillman, and K. Yvonne Woodworth for their help with data collection and transcription and Zoe and Lucie for inspiration. This research was supported by a grant from the National Science Foundation (BCS-0418423). 


\section{References}

Bates, E., Dale, P.S., and Thal, D. (1995). Individual Differences and Their Implications for Theories of Language Development. In Fletcher, P. \& MacWhinney, B. (Eds.), The handbook of child language (pp. 96-151), Oxford, England: Blackwell Publishers.

Bates, E. \& Goodman, J. C. (1997). On the inseparability of grammar and the lexicon: Evidence from acquisition, aphasia, and real-time processing. Language and Cognitive Processes. 12, 507-584.

Bates, E., Marchman, V., Thal, D., Fenson, L., Dale, P., Reznick, J.S., Reilly, J., \& Hartung, J. (1994). Developmental and stylistic variation in the composition of early vocabulary. Journal of Child Language, 21(1), 85-124.

Bauer, P.J., Hertsgaard, L.A., Dropik, P., \& Daly, B.P. (1998). When even arbitrary order becomes important: Developments in reliable temporal sequencing of arbitrarily ordered events. Memory, 6, 165-198.

Behrens, H. (2006). The input-output relationship in first language acquisition. Language and Cognitive Processes, 21, 2-24.

Bellugi, U., Marks, S., Bihrle, A., \& Sabo, H. (1988). Dissociation between language and cognitive functions in Williams syndrome. In D. Bishop \& K. Mogford (Eds.), Language development in exceptional circumstances (pp. 177-189). London: Churchill Livingstone

Bloom, L. (1973) One word at a time: the use of single-word utterances before syntax. The Hague: Mouton.

Bornstein M. H., Cote L. R., Maital S., Painter, K., Park, S. Y., Pascual L., Pecheux M. G., Ruel J., Venuti P. \& Vyt, A. (2004). Cross-linguistic analysis of vocabulary in young children: 
Spanish, Dutch, French, Hebrew, Italian, Korean, and American English. Child Development, 75(4):1115-39.

Brent, M. R. \& Siskind, J. M (2001). The role of exposure to isolated words in early vocabulary development. Cognition, 81, 31-44.

Bricker, D. \& Squires, J. (1999 ). Ages and stages questionnaires: A parent-completed childmonitoring system, (2nd ed). Baltimore : Paul Brookes.

Brown, R. (1973). A first language: The early stages. Cambridge, MA: Harvard University Press.

Brownell, C. (1988). Combinatorial skills: Converging developments over the second year. Child Development, 59, 675-685.

Camras, L., Perlman, S., Fries, A., \& Pollak S. (2006). Post-institutionalized Chinese and Eastern European children: Heterogeneity in the development of emotion understanding. International Journal of Behavioral Development, 30(3), 193-199.

Choi, S. \& Gopnik, A. (1995). Early acquisition of verbs in Korean: A cross-linguistic study. Journal of Child Language, 22(3), pp. 497-529.

Clahsen, H. (1990). The comparative study of first and second language development. Studies in Second Language Acquisition, 12, 135-54.

Conboy, B.T. \& Thal, D. (2006). Ties between the lexicon and grammar: Cross-sectional and longitudinal studies of bilingual toddlers. Child Development,77(3), 712-735.

Cromer, R. (1974). The development of language and cognition: The cognition hypothesis. In B. Foss (Ed.), New perspectives in child development (pp. 184-252). Harmondsworth: Penguin. 
Curtiss, S. (1989). Abnormal language acquisition and the modularity of language. In F. Newmeyer (Ed.), Linguistics: The Cambridge survey (Vol.2, pp. 96-116). Cambridge, UK: Cambridge University Press.

Dale, P. S., and Fenson, L. (1996). Lexical development norms for young children. Behavioral Research Methods, Instruments, \& Computers, 28, 125-127.

Doran, E.W. (1907) A study of vocabularies. Pedagogical Seminary 14, 4: 401-438.

Fenson, L., Dale, P. S., Reznick, J. S., Thal, D., Bates, E., Hartung, J. P., et al. (1993). MacArthur Communicative Development Inventories: User's guide and technical manual. San Diego, CA: Singular.

Fenson, L., Dale, P.S., Reznick, J.S., Bates, E., Thal, D., \& Pethick, S. (1994). Variability in early communicative development. Monographs of the Society for Research in Child Development. 59(5), v-173.

Fenson, L. \& Ramsay, D.S. (1980). Decentration and integration of the child's play in the second year. Child Development, 51, 171-178.

Fries, A. \& Pollak S. (2004). Emotion understanding in postinstitutionalized Eastern European children. Development and Psychopathology, 16(2), 355-369.

Ganger, J. \& Brent, M. (2004). Re-examining the vocabulary spurt. Developmental Psychology, 4, 621-632.

Gentner, D. (1982). Why nouns are learned before verbs: Linguistic relativity versus natural partitioning. In S.A. Kuczaj, II (Ed.), Language development: Vol 2. language, thought, and culture (pp. 31-53). Hillsdale, NJ: Erlbaum. 
Gentner, D., \& Boroditsky, L. (2001). Individuation, relativity, and early word learning. In M.

Bowerman \& S. Levinson (Eds.), Language acquisition and conceptual development.

Cambridge, England: Cambridge University Press.

Geren, J., Snedeker, J. \& Shafto, C. (in preparation). "Lexical and grammatical development in children adopted from China and Eastern Europe.”

Gertner, Y., Fisher, C., \& Eisengart, J. (2006). Learning words and rules: Abstract knowledge of word order in early sentence comprehension. Psychological Science, 17, 684-691.

Gillette, J., Gleitman, H., Gleitman, L., \& Lederer, A. (1999). Human simulation of vocabulary learning. Cognition, 73, 135-176.

Gleitman, L.R. (1981). Maturational determinants of language growth. Cognition, 10, 103-114.

Gleitman, L.R., Cassidy, K., Papafragou, A., Nappa, R., \& Trueswell, J.T. (2005) Hard words, Language Learning and Development, 1:1., 23-64

Glennen, S., \& Masters, M. G. (2002). Typical and atypical language development in infants and toddlers adopted from Eastern Europe. American Journal of Speech-Language Pathology, $11,417-433$.

Goldin-Meadow, S. \& Feldman, H. (1977). The development of language-like communication without a language model. Science, 197, 401-403.

Gombert, J.E. (1992). Metalinguistic development. Chicago: University of Chicago Press.

Greenfield, P.M. (1978). Developmental processes in the language learning of child and chimp. Behavioral and Brain Sciences, 4, 573-574.

Havasi, C. \& Snedeker, J. (2004). The Adaptability of Language-Specific Verb Lexicalization Biases. Proceedings of the Twenty-sixth Annual Conference of the Cognitive Science Society. Mahwah, NJ, USA: Lawrence Erlbaum Associates, Inc. 
Hoff, E. (2001). Language development. Belmont, CA: Wadsworth Thomson Learning.

Huttenlocher, J., Smiley, P., \& Ratner, H. (1983). What do word meanings reveal about conceptual development? In T. Wannamacher \& W. Seiler (Eds.), The development of word meanings and concepts (pp. 210-233). Berlin: Springer-Verlag.

Kim, M., McGregor, K. \& Thompson, C. (2000). Early lexical development in English- and Korean-speaking children: Language-general and language-specific patterns. Journal of Child Language, 27(2), pp. 225-254.

Laing, E., Butterworth, G., Ansari, D., Gsödl, M., Longhi, E., Panagiotaki, G., Paterson, S., \& Karmiloff-Smith, A. (2002). Atypical development of language and social communication in toddlers with Williams syndrome. Developmental Science, 5, 233-246

Landau, B. \& Gleitman, L.R. (1985). Language and experience: Evidence from the blind child. Cambridge, MA: Harvard University Press.

Lenneberg, E. (1967). Biological foundations of language. New York: Wiley.

Levy, E. \& Nelson, K. (1994). Words in discourse: a dialectical approach to the acquisition of meaning and use. Journal of Child Language, 21(2), 367-89.

Locke, J.L. (1997). A theory of neurolinguistic development. Brain and Language, 58, 265-326.

Lucariello, J., \& Nelson, K. (1987). Remembering and planning talk between mothers and children. Discourse Processes, 10, 219-235.

MacWhinney, B. (2000). The CHILDES project: Tools for analyzing talk. Mahwah, NJ: Erlbaum.

Marchman, V., Martínez-Sussmann, C., \& Dale, P. (2004). The language-specific nature of grammatical development: Evidence from bilingual language learners. Developmental Science, 7(2), pp. 212-224. 
McCall, R. B., Parke, R. D., \& Kavanaugh, R. D. (1977). Imitation of live and televised models bychildren one to three years of age. Monographs of the Society for Research in Child Development, 42(5).

McCarthy, D. A. (1930). The language development of the preschool child. Minneapolis: University of Minnesota Press.

Miller, L. \& Hendrie, N. (2000). Health of children adopted from China. Pediatrics,105(6):e76

Morgan, J., Shi, R. \& Allopena, P. (1996). Perceptual bases of rudimentary grammatical categories. In J. Morgan \& K. Demuth (Eds.), Signal to Syntax (pp. 263-287). Cambridge, MA: MIT Press.

Nelson, K. (1996). Language in cognitive development: The emergence of the mediated mind. New York: Cambridge University Press.

Newport, E. (1990). Maturational constraints on language learning. Cognitive Science, 14, 1128.

Nice, M. (1925). Length of sentences as a criterion of child's progress in speech. Journal of Educational Psychology, 16:370-9.

O’Grady, William. 1987. Principles of grammar and learning. Chicago: University of Chicago Press.

Pallier, C., Dehaene, S., Poline, J., LeBihan, D., Argenti, A., Dupoux, E. \& Mehler, J. (2003). Brain imaging of language plasticity in adopted adults. Cerebral Cortex, 13, 155-161.

Pinker, S. (1984). Language learnability and language development. Cambridge, MA: Harvard University Press.

Pollock K. (2005). Early Language Growth in Children Adopted from China: Issues and Preliminary Normative Data. Seminars in Speech and Language 26, 22-32. 
Raudenbush, S. W., A. S. Bryk, and R. Congdon. 2005. HLM6.03: Hierarchical Linear and Nonlinear Modeling. Chicago: Scientific Software International.

Redington, M., Chater, N., \& Finch, S. (1998). Distributional information: A powerful cue for acquiring syntactic categories. Cognitive Science, 22, 425-469.

Roberts, J., Pollock, K., Krakow, R., Price, J., Fulmer, K., \& Wang, P. (2005). Language

Development in Preschool-Age Children Adopted from China. Journal of Speech, Language, and Hearing Research, 48(1), pp. 93-107.

Rondal, J.A. (2003). Atypical language development in individual with mental retardation. In L. Abbeduto (Ed.), Language and communication in mental retardation. (Vol. 27, pp. 281308). New York: Academic Press.

Sachs, J. (1983). Talking about the There and Then: the emergence of displaced reference in parent-child discourse. In K. E. Nelson (Ed.), Children's Language (Vol. 4, pp. 1-28). Hillsdale: Lawrence Erlbaum Associates.

Senghas, A. (2003). Intergenerational influence and ontogenetic development in the emergence of spatial grammar in Nicaraguan Sign Language, Cognitive Development, 18, 511-531.

Selkirk, E. O. (1996). The prosodic structure of function words. In Signal to Syntax, eds. J. L. Morgan and K. Demuth. Mahwah, NJ: Lawrence Erlbaum. 187-213.

Shore, C. (1986). Combinatorial play: Conceptual development and early multiword speech. Developmental Psychology, 22, 184-190.

Shore, C., O'Connell, B. \& Bates, E. (1984). First sentences in language and symbolic play. Developmental Psychology, 20, 872-880. 
Singer, J. D., \& Willett, J.B. (2003). Applied longitudinal data analysis: Modeling change and event occurrence. New York: Oxford University Press

Singer-Harris N, Bellugi U, Bates E, Rossen M, \& Jones W. (1997). Emerging language in two genetically based neurodevelopmental disorders. In Thal D, Reilly J, eds. Special issue on Origins of Communication Disorders, Developmental Neuropsychology;13(3):345-370

Sloutsky, V.M. (1997). Institutional care and developmental outcomes of 6- and 7-year-old children: A contextualist perspective. International Journal of Behavioral Development, 20(1), pp. 131-151.

Snedeker, J., Geren, J. \& Shafto, C. (2007). Starting over: International adoption as a natural experiment in language development. Psychological Science. 18(1), 79-87.

Snedeker, J. \& Gleitman, L. (2004). Why it is hard to label our concepts. In Hall, G. \& Waxman, S. (Eds), Weaving a Lexicon (pp. 257-294). Cambridge, MA: MIT Press.

Snedeker, J., Li, P. \& Yuan, S. (2003). Cross-Cultural Differences in the Input to Early Word Learning. Proceedings of the 25th Annual Cognitive Science Conference. Mahwah, NJ: Lawrence Erlbaum Associates, Inc.

Sugarman, S. (1983). Developmental change in early representational intelligence: Evidence from spatial classification strategies and related verbal expressions. Cognitive Psychology, 14, 410-449.

Talmy, L. (2000). Toward a Cognitive Semantics, Volume 2. Cambridge, MA: MIT

Tardif, T. (1996). Nouns are not always learned before verbs: Evidence from Mandarin speakers' early vocabularies. Developmental Psychology, 32(3), pp. 492-504.

Tardif, T., Gelman, S. \& Xu, F. (1999). Putting the 'noun bias' in context: A comparison of English and Mandarin. Child Development, 70, 620-635. 
Tare, M., \& Shatz, M. (2005). Children's use and understanding of expressions of time. Paper presented at the Biennial Meeting of the Society for Research in Child Development, Atlanta, April 7-10.

Tare, M., Shatz, M., \& Gilbertson, L. (2008). Maternal uses of non-object terms in childdirected speech: Color, number and time. First Language, 28(1), 87-100

Thal, D., O'Hanlon, L., Clemmons, M. \& Frailin, L. (1999). Validity of a parent report measure of vocabulary and syntax for preschool children with language impairment. Journal of Speech, Language \& Hearing Disorders;42:482-496.

The St. Petersburg-USA Orphanage Research Team (2005). Characteristics of children, caregivers, and orphanages for young children in St. Petersburg, Russian Federation. Journal of Applied Developmental Psychology, 26(5), 477-506.

Tomasello, M. (1992). First Verbs: A Case Study of Early Lexical Development. Cambridge: Cambridge University Press.

U.S. Department of State (2008). Total Adoptions to the United States. Retrieved February 20, 2009, from http://adoption.state.gov/news/total_chart.html

Wexler, K. (1999). Maturation and growth of grammar. In W.C. Ritchie \& T.K. Bhatia (Eds.), Handbook of Child Language Acquisition (pp. 55-110). San Diego: Academic Press.

Yagmurlu, B., Berument, S., Celimli, S. (2005). The role of institution and home contexts in theory of mind development. Journal of Applied Developmental Psychology, 26(5), 521537. 
Table 1: Background Information about Participants

\begin{tabular}{|c|c|c|c|c|c|c|c|}
\hline Participant & Sex & $\begin{array}{l}\text { Age at } \\
\text { arrival }\end{array}$ & $\begin{array}{l}\text { Birth Language } \\
\quad \text { (country) }\end{array}$ & $\begin{array}{l}\text { Developmental } \\
\text { concerns* }\end{array}$ & $\begin{array}{l}\text { Knowledge of birth language } \\
\text { (first / final session) }\end{array}$ & $\begin{array}{l}\text { Continued exposure to birth language } \\
\text { (first / final session) }\end{array}$ & $\begin{array}{l}\text { Frequency of use of bi } \\
\text { language (first / final ses }\end{array}$ \\
\hline \multicolumn{8}{|c|}{ Preschool Adoptees } \\
\hline A & M & $2 ; 5$ & Russian & 1,2 & $\leq 5$ words / none & never / never & $50 \% /<25 \%$ \\
\hline B & $\mathrm{F}$ & $5 ; 0$ & Russian & none & $\begin{array}{l}\text { 4-5 word sentences / 5-15 } \\
\text { words }\end{array}$ & daily sibling** / never & $>75 \% /$ never \\
\hline $\mathrm{C}$ & $\mathrm{F}$ & $3 ; 1$ & Russian (Belarus) & none & $4-5$ word sentences $/ \leq 5$ words & $\begin{array}{l}\text { sitter } 1 \text { day a week } / 2 \text { days a month } \\
\text { (sitter) }\end{array}$ & $>75 \% /$ never \\
\hline $\mathrm{D}$ & $\mathrm{F}$ & $5 ; 6$ & Russian & 1 & 4-5 word sentences / none & never / rarely & $>75 \% /$ never \\
\hline $\mathrm{E}$ & $\mathrm{M}$ & $4 ; 3$ & Mandarin & 3 & 4-5 word sentences / no data & never / no data & $>75 \% /$ no data \\
\hline $\mathrm{F}$ & $\mathrm{M}$ & $5 ; 4$ & Russian & 2 & 4-5 word sentences / none & never / rarely & $>75 \% /$ never \\
\hline $\mathrm{G}$ & M & $4 ; 2$ & Russian & 2 & 4-5 word sentences / none & never / rarely & $>75 \% /$ never \\
\hline $\mathrm{H}$ & $\mathrm{F}$ & $2 ; 9$ & Longyou (China) & 3 & $4-5$ word sentences $/ \leq 5$ words & never / never & $>75 \% /$ never \\
\hline I & $\mathrm{F}$ & $3 ; 1$ & Russian & 3 & $\begin{array}{c}\text { some } 2 \text {-word phrases / } \leq 5 \\
\text { words }\end{array}$ & never / rarely & $<25 \% /$ never \\
\hline \multicolumn{8}{|c|}{ Infant Adoptees } \\
\hline 1 & $\mathrm{~F}$ & $1 ; 4$ & Mandarin & none & none / 5-15 words & never / 1 class each week & never $/<25 \%$ \\
\hline 2 & $\mathrm{~F}$ & $1 ; 2$ & Cantonese & 1 & never learned & never / never & never / never \\
\hline 3 & $\mathrm{~F}$ & $1 ; 3$ & Mandarin & 1 & never learned & never / never & never / never \\
\hline 4 & M & $0 ; 6$ & Russian & 1 & never learned & never / rarely & never / never \\
\hline 5 & $\mathrm{~F}$ & $0 ; 10$ & Cantonese & none & never learned & never / never & never / never \\
\hline 6 & $\mathrm{~F}$ & $0 ; 11$ & Cantonese & none & never learned & never / rarely & never / never \\
\hline 7 & $\mathrm{~F}$ & $1 ; 4$ & Mandarin & none & never learned & never / rarely & never / never \\
\hline 8 & $\mathrm{~F}$ & $0 ; 7$ & Russian (Kazakhstan) & none & never learned & never / rarely & never / never \\
\hline 9 & $\mathrm{~F}$ & $1 ; 0$ & Mandarin & 1 & none / some 2-word phrases & 1 class a week / 1 class a week & never $/<25 \%$ \\
\hline 10 & $\mathrm{~F}$ & $1 ; 3$ & Russian & none & never learned & never / never & never / never \\
\hline 11 & $\mathrm{~F}$ & $1 ; 0$ & Mandarin & none & $\leq 5$ words $/ \leq 5$ words & never / rarely & never / never \\
\hline 12 & $\mathrm{~F}$ & $1 ; 1$ & Cantonese & none & never learned & never / never & never / never \\
\hline 13 & $\mathrm{~F}$ & $0 ; 11$ & Cantonese & no data & none / no data & never / no data & never / no data \\
\hline 14 & $\mathrm{~F}$ & $1 ; 3$ & Cantonese & none & $\leq 5$ words / none & never / rarely & never / never \\
\hline
\end{tabular}

* $1=$ developmental delays, 2 = hearing related (all participants had normal hearing in at least one ear), $3=$ physical health.

** Younger adoptive sibling, adopted at same time. 
Table 2: Summary of Data Collected

$\underline{\text { First Session }}$

$\begin{array}{cccccc}\text { Subject } & \begin{array}{c}\text { \# of } \\ \text { Sessions }\end{array} & \text { Age of } & \text { Time in } & \text { CDI } & \text { Combining } \\ & & & \text { US } & \text { Vocab } & \text { Words } \\ & & & & \end{array}$

Preschool Adoptees

\begin{tabular}{|c|c|c|c|c|c|c|c|c|}
\hline A & 9 & $2 ; 7$ & 1.6 & 12 & never & 13 & 625 & often \\
\hline B & 6 & $5 ; 3$ & 0.6 & 29 & sometimes & 12 & 678 & often \\
\hline $\mathrm{C}$ & 8 & $3 ; 3$ & 1.1 & 10 & never & 12 & 580 & often \\
\hline $\mathrm{D}$ & 8 & $5 ; 8$ & 1.2 & 32 & never & 12 & 482 & often \\
\hline $\mathrm{E}$ & 7 & $4 ; 4$ & 0.3 & 27 & sometimes & 14 & 647 & often \\
\hline $\mathrm{F}$ & 8 & $5 ; 4$ & 1.1 & 84 & never & 15 & 647 & often \\
\hline G & 8 & $4 ; 3$ & 1.1 & 72 & never & 15 & 663 & often \\
\hline $\mathrm{H}$ & 8 & $2 ; 11$ & 1.1 & 24 & never & 13 & 640 & often \\
\hline I & 6 & $3 ; 1$ & 3.2 & 197 & often & 12 & 602 & often \\
\hline mean & 7.6 & $4 ; 2$ & 1.3 & 54 & & 13.1 & 618 & \\
\hline \multicolumn{9}{|c|}{ Infant Adoptees } \\
\hline 1 & 12 & $1 ; 11$ & 2.5 & 7 & never & 9 & 412 & often \\
\hline 2 & 12 & $1 ; 10$ & 6.4 & 8 & never & 12 & 419 & often \\
\hline 3 & 12 & $1 ; 10$ & 5.6 & 14 & never & 11 & 181 & sometimes \\
\hline 4 & 12 & $1 ; 10$ & 6.0 & 10 & sometimes & 11 & 538 & often \\
\hline 5 & 12 & $1 ; 8$ & 5.4 & 6 & never & 10 & 568 & often \\
\hline 6 & 12 & $1 ; 5$ & 6.0 & 14 & never & 11 & 532 & often \\
\hline 7 & 12 & $1 ; 6$ & 0.9 & 7 & never & 11 & 406 & often \\
\hline 8 & 11 & $1 ; 6$ & 10.4 & 30 & sometimes & 12 & 615 & often \\
\hline 9 & 10 & $1 ; 4$ & 8.8 & 159 & sometimes & 15 & 601 & often \\
\hline 10 & 12 & $1 ; 9$ & 6.0 & 22 & never & 11 & 598 & often \\
\hline 11 & 11 & $1 ; 3$ & 3.1 & 23 & never & 11 & 570 & often \\
\hline 12 & 11 & $1 ; 10$ & 9.6 & 25 & never & 12 & 427 & often \\
\hline 13 & 11 & $1 ; 10$ & 9.4 & 8 & never & 9 & 119 & often \\
\hline 14 & 12 & $1 ; 7$ & 6.7 & 107 & never & 15 & 680 & often \\
\hline mean & 11.6 & $1 ; 7$ & 6.8 & 31 & & 11.4 & 476 & \\
\hline
\end{tabular}

* Age of Onset: age at which child had a productive vocabulary of approximately 20 English words. See text for details. 
Table 3: Hierarchical Models of Vocabulary Growth

\begin{tabular}{|c|c|c|c|c|c|c|c|c|}
\hline & & Parameter & $\begin{array}{l}\text { Unconditional } \\
\text { Model }\end{array}$ & $\begin{array}{l}\text { Linear } \\
\text { Growth } \\
\text { Model }\end{array}$ & $\begin{array}{l}\text { Quadratic } \\
\text { Growth } \\
\text { Model }\end{array}$ & $\begin{array}{l}\text { Quadratic } \\
\text { Growth } \\
\text { Model } 2\end{array}$ & $\begin{array}{c}\text { Quadratic } \\
\text { Growth } \\
\text { Model 3 } \\
\end{array}$ & $\begin{array}{l}\text { Quadratic } \\
\text { Growth } \\
\text { Model } 4\end{array}$ \\
\hline \multicolumn{9}{|l|}{$\underline{\text { Fixed Effects }}$} \\
\hline Initial vocabulary size & Intercept & $\gamma_{00}$ & $\begin{array}{c}249.70^{* *} \\
(19.28)\end{array}$ & $\begin{array}{c}-7.29 \\
(11.28)\end{array}$ & $\begin{array}{c}4.20 \\
(5.76)\end{array}$ & $\begin{array}{l}4.78 \\
(5.73)\end{array}$ & $\begin{array}{r}4.62 \\
(5.71) \\
\end{array}$ & $\begin{array}{l}-9.70 \\
(7.11)\end{array}$ \\
\hline$\pi_{0 \mathrm{i}}$ & $\begin{array}{l}\text { Group: preschooler } \\
\text { relative to infant }\end{array}$ & $\gamma_{01}$ & & & & & & $\begin{array}{c}7.88 \\
(12.10)\end{array}$ \\
\hline $\begin{array}{l}\text { Rate of Change } \\
\text { (time since } 20 \text { words) }\end{array}$ & Intercept & $\gamma_{10}$ & & $\begin{array}{c}53.08^{* *} \\
(4.88)\end{array}$ & $\begin{array}{r}47.44^{* *} \\
(10.03)\end{array}$ & $\begin{array}{c}35.64^{* *} \\
(8.65)\end{array}$ & $\begin{array}{r}22.64 * \\
(8.54) \\
\end{array}$ & $\begin{array}{l}20.46^{*} \\
(9.09)\end{array}$ \\
\hline$\pi_{2 \mathrm{i}}$ & $\begin{array}{l}\text { Group: preschooler } \\
\text { relative to infant }\end{array}$ & $\gamma_{11}$ & & & & $\begin{array}{c}28.32 * * \\
(6.89)\end{array}$ & $\begin{array}{l}62.66 * * \\
(12.32) \\
\end{array}$ & $\begin{array}{l}69.07 * * \\
(14.81)\end{array}$ \\
\hline $\begin{array}{l}\text { Acceleration } \\
\text { (time since } 20 \text { squared) }\end{array}$ & Intercept & $\gamma_{20}$ & & & $\begin{array}{c}0.391 \\
(0.770)\end{array}$ & $\begin{array}{c}0.504 \\
(0.774)\end{array}$ & $\begin{array}{l}2.03 * * \\
(\mathbf{0 . 7 5 8 )} \\
\end{array}$ & $\begin{array}{l}2.16^{* *} \\
(0.783)\end{array}$ \\
\hline$\pi_{2 \mathrm{i}}$ & $\begin{array}{l}\text { Group: preschooler } \\
\text { relative to infant }\end{array}$ & $\gamma_{21}$ & & & & & $\begin{array}{c}-4.11 * * \\
(1.20) \\
\end{array}$ & $\begin{array}{c}-4.52 * * \\
(1.31)\end{array}$ \\
\hline \multicolumn{9}{|l|}{ Variance Components } \\
\hline $\begin{array}{l}\text { Level } 1 \\
\text { Level } 2\end{array}$ & $\begin{array}{l}\text { Within person } \\
\text { Initial vocabulary } \\
\text { Rate of change } \\
\text { Acceleration }\end{array}$ & $\begin{array}{l}\sigma_{\varepsilon}^{2} \\
\sigma^{2}{ }_{0} \\
\sigma_{1}^{2} \\
\sigma^{2}{ }_{2}\end{array}$ & $\begin{array}{c}32840.47^{* *} \\
4335.91 * *\end{array}$ & $\begin{array}{l}2042.14^{* *} \\
1908.79^{* *} \\
494.62^{* *}\end{array}$ & $\begin{array}{c}897.62^{* *} \\
104.43 \\
2088.75^{* *} \\
11.76^{* *}\end{array}$ & $\begin{array}{c}884.22 * * \\
104.49 \\
1335.22^{* *} \\
11.92^{* *}\end{array}$ & $\begin{array}{c}897.14 * * \\
93.39 \\
937.07 * * \\
6.76 * *\end{array}$ & $\begin{array}{c}894.60^{* *} \\
94.31 \\
950.38^{* *} \\
6.90^{* *}\end{array}$ \\
\hline \multicolumn{9}{|c|}{ Pseudo R2 statistic and Goodness-of-fit } \\
\hline & $\begin{array}{l}\mathrm{R}_{\mathrm{y}, \mathrm{y}}^{2} \\
\text { Deviance } \\
\text { AIC } \\
\text { BIC } \\
\text { \# parameters }\end{array}$ & & $\begin{array}{c}2718.05 \\
2724.05 \\
2727.46 \\
3\end{array}$ & $\begin{array}{c}0.627 \\
2261.60 \\
2273.60 \\
2280.41 \\
6\end{array}$ & $\begin{array}{c}0.627 \\
2144.20 \\
2164.20 \\
2175.55 \\
10\end{array}$ & $\begin{array}{c}0.715 \\
2134.91 \\
2156.91 \\
2169.40 \\
11\end{array}$ & $\begin{array}{c}0.758 \\
2124.80 \\
2148.80 \\
2162.43 \\
12\end{array}$ & $\begin{array}{c}0.757 \\
2124.15 \\
2150.15 \\
2164.91 \\
13\end{array}$ \\
\hline
\end{tabular}

$* \mathrm{p}<.05, * * \mathrm{p}<.005$. Outlined cells indicate the model selected on the basis of fit; the parameter estimates and standard errors for the predictors in that model; and the total variance accounted for by that model. The grey cells indicate the effects of participant group. 
Table 4: Hierarchical Models of Social Word Percentage in Children's Vocabularies between 0 and 230 words

\begin{tabular}{|c|c|c|c|c|c|c|}
\hline & & Parameter & $\begin{array}{l}\text { Unconditional } \\
\text { Model }\end{array}$ & $\begin{array}{c}\text { Vocabulary } \\
\text { Growth Model }\end{array}$ & $\begin{array}{c}\text { Vocabulary } \\
\text { Growth Model } 2\end{array}$ & $\begin{array}{c}\text { Vocabulary } \\
\text { Growth Model } 3\end{array}$ \\
\hline \multicolumn{7}{|l|}{ Fixed Effects } \\
\hline Initial percentage & Intercept & $\gamma_{00}$ & $\begin{array}{c}34.05^{* *} \\
(2.34)\end{array}$ & $\begin{array}{c}52.60 * * \\
(3.15) \\
\end{array}$ & $\begin{array}{c}52.26^{* *} \\
(3.21)\end{array}$ & $\begin{array}{c}52.87^{* *} \\
(3.16)\end{array}$ \\
\hline$\pi_{0 \mathrm{i}}$ & $\begin{array}{l}\text { Group: preschooler } \\
\text { relative to infant }\end{array}$ & $\gamma_{01}$ & & & $\begin{array}{c}1.65 \\
(2.64)\end{array}$ & \\
\hline Rate of Change & Intercept & $\gamma_{10}$ & & $\begin{array}{c}-0.223 * * \\
(0.025) \\
\end{array}$ & $\begin{array}{c}-0.224^{* *} \\
(0.025)\end{array}$ & $\begin{array}{c}-0.230^{* *} \\
(0.026)\end{array}$ \\
\hline$\pi_{2 \mathrm{i}}$ & $\begin{array}{l}\text { Group: preschooler } \\
\text { relative to infant }\end{array}$ & $\gamma_{11}$ & & & & $(0.020)$ \\
\hline \multicolumn{7}{|c|}{ Variance Components } \\
\hline Level 1 & Within person & $\sigma_{\varepsilon}^{2}$ & $358.30 * *$ & $120.10 * *$ & $119.62 * *$ & $119.62 * *$ \\
\hline \multirow[t]{2}{*}{ Level 2} & Initial percentage & $\sigma_{0}^{2}$ & $48.23^{* *}$ & $130.58 * *$ & $131.14 * *$ & $128.70 * *$ \\
\hline & Rate of change & $\sigma_{1}^{2}$ & & $0.00720 * *$ & $0.00726^{* *}$ & $0.00712^{* *}$ \\
\hline \multicolumn{7}{|c|}{ Pseudo R2 statistic and Goodness-of-fit } \\
\hline & $\mathrm{R}_{\mathrm{y}, \mathrm{y}}^{2}$ & & & 0.584 & 0.584 & 0.587 \\
\hline & Deviance & & 1135.32 & 1005.71 & 1005.31 & 1005.05 \\
\hline & AIC & & 1141.32 & 1017.71 & 1019.31 & 1019.05 \\
\hline & $\mathrm{BIC}$ & & 1150.73 & 1036.52 & 1041.26 & 1041.00 \\
\hline & \# of parameters & & 3 & 6 & 7 & 7 \\
\hline
\end{tabular}

$* \mathrm{p}<.05, * * \mathrm{p}<.005$. Outlined cells indicate the model selected on the basis of fit; the parameter estimates and standard errors for the predictors in that model; and the total variance accounted for by that model. The grey cells indicate the effects of participant group. 


\section{Table 5: Hierarchical Models of Noun Percentage in Children's Vocabularies between 0 and 230 words}

\begin{tabular}{|c|c|c|c|c|c|c|}
\hline & & Parameter & $\begin{array}{l}\text { Unconditional } \\
\text { Model }\end{array}$ & $\begin{array}{l}\text { Vocabulary } \\
\text { Growth Model }\end{array}$ & $\begin{array}{c}\text { Vocabulary } \\
\text { Growth Model } 2\end{array}$ & $\begin{array}{c}\text { Vocabulary } \\
\text { Growth Model } 3\end{array}$ \\
\hline \multicolumn{7}{|l|}{ Fixed Effects } \\
\hline Initial percentage & Intercept & $\gamma_{00}$ & $\begin{array}{c}45.10 * * \\
(2.30)\end{array}$ & $\begin{array}{c}34.99 * * \\
(3.32) \\
\end{array}$ & $\begin{array}{c}35.75 * * \\
(3.48)\end{array}$ & $\begin{array}{c}34.93 * * \\
(3.31)\end{array}$ \\
\hline$\pi_{0 \mathrm{i}}$ & $\begin{array}{l}\text { Group: preschooler } \\
\text { relative to infant }\end{array}$ & $\gamma_{01}$ & & & $\begin{array}{l}-2.49 \\
(3.30)\end{array}$ & \\
\hline Rate of Change & Intercept & $\gamma_{10}$ & & $\begin{array}{l}0.115 * * \\
(0.020) \\
\end{array}$ & $\begin{array}{l}0.116^{* *} \\
(0.020)\end{array}$ & $\begin{array}{l}0.121 * * \\
(0.021)\end{array}$ \\
\hline$\pi_{2 \mathrm{i}}$ & $\begin{array}{l}\text { Group: preschooler } \\
\text { relative to infant }\end{array}$ & $\gamma_{11}$ & & & & $\begin{array}{l}-0.015 \\
(0.019)\end{array}$ \\
\hline \multicolumn{7}{|c|}{$\underline{\text { Variance Components }}$} \\
\hline Level 1 & Within person & $\sigma_{\varepsilon}^{2}$ & $151.22 * *$ & $96.64 * *$ & $96.23 * *$ & $96.35 * *$ \\
\hline \multirow[t]{2}{*}{ Level 2} & Initial percentage & $\sigma_{0}^{2}$ & $82.88 * *$ & $156.90 * *$ & $157.91 * *$ & $156.30 * *$ \\
\hline & Rate of change & $\sigma_{1}^{2}$ & & 0.00305 & 0.00317 & 0.00317 \\
\hline \multicolumn{7}{|c|}{$\underline{\text { Pseudo R2 statistic and Goodness-of-fit }}$} \\
\hline & $\mathrm{R}_{\mathrm{y}, \mathrm{y}}^{2}$ & & & 0.296 & 0.297 & 0.301 \\
\hline & Deviance & & 1042.08 & 987.36 & 986.77 & 986.68 \\
\hline & AIC & & 1048.08 & 999.36 & 1000.77 & 1000.68 \\
\hline & $\mathrm{BIC}$ & & 1057.49 & 1018.17 & 1022.72 & 1022.63 \\
\hline & \# of parameters & & 3 & 6 & 7 & 7 \\
\hline
\end{tabular}

$* \mathrm{p}<.05, * * \mathrm{p}<.005$. Outlined cells indicate the model selected on the basis of fit; the parameter estimates and standard errors for the predictors in that model; and the total variance accounted for by that model. The grey cells indicate the effects of participant group. 
Table 6: Hierarchical Models of Noun Percentage in Children's Vocabularies between 200 and 610 words

\begin{tabular}{|c|c|c|c|c|c|c|}
\hline & & Parameter & $\begin{array}{l}\text { Unconditional } \\
\text { Model }\end{array}$ & $\begin{array}{l}\text { Vocabulary } \\
\text { Growth Model }\end{array}$ & $\begin{array}{c}\text { Vocabulary } \\
\text { Growth Model } 2\end{array}$ & $\begin{array}{c}\text { Vocabulary } \\
\text { Growth Model }\end{array}$ \\
\hline \multicolumn{7}{|l|}{$\underline{\text { Fixed Effects }}$} \\
\hline Initial percentage & Intercept & $\gamma_{00}$ & $\begin{array}{l}48.85 * * \\
(0.943)\end{array}$ & $\begin{array}{c}54.70 * * \\
(1.73)\end{array}$ & $\begin{array}{c}55.37 * * \\
(1.76)\end{array}$ & $\begin{array}{l}54.60 * * \\
(1.73)\end{array}$ \\
\hline$\pi_{0 \mathrm{i}}$ & $\begin{array}{l}\text { Group: preschooler } \\
\text { relative to infant }\end{array}$ & $\gamma_{01}$ & & & $\begin{array}{l}-1.80 \\
(1.09)\end{array}$ & \\
\hline Rate of Change & Intercept & $\gamma_{10}$ & & $\begin{array}{c}-0.029 * * \\
(0.005) \\
\end{array}$ & $\begin{array}{c}-0.029^{* *} \\
(0.005)\end{array}$ & $\begin{array}{c}-0.027^{* *} \\
(0.005)\end{array}$ \\
\hline$\pi_{2 \mathrm{i}}$ & $\begin{array}{l}\text { Group: preschooler } \\
\text { relative to infant }\end{array}$ & $\gamma_{11}$ & & & & $\begin{array}{c}-0.005 \\
(0.003)\end{array}$ \\
\hline \multicolumn{7}{|c|}{$\underline{\text { Variance Components }}$} \\
\hline Level 1 & Within person & $\sigma_{\varepsilon}^{2}$ & $31.97 * *$ & $9.69 * *$ & $9.42 * *$ & $9.42 * *$ \\
\hline \multirow[t]{2}{*}{ Level 2} & Initial percentage & $\sigma_{0}^{2}$ & $10.04 * *$ & $50.67^{* *}$ & $49.82 * *$ & $50.84 * *$ \\
\hline & Rate of change & $\sigma_{1}^{2}$ & & $0.0034 * *$ & $0.0035^{* *}$ & $0.0035^{* *}$ \\
\hline \multicolumn{7}{|c|}{ Pseudo R2 statistic and Goodness-of-fit } \\
\hline & $R_{y, y}^{2}$ & & & 0.369 & 0.392 & 0.382 \\
\hline & Deviance & & 597.71 & 514.13 & 511.35 & 511.69 \\
\hline & AIC & & 603.71 & 526.13 & 525.35 & 525.69 \\
\hline & BIC & & 612.84 & 544.40 & 546.66 & 547.00 \\
\hline & \# of parameters & & 3 & 6 & 7 & 7 \\
\hline
\end{tabular}

$* \mathrm{p}<.05, * * \mathrm{p}<.005$. Outlined cells indicate the model selected on the basis of fit; the parameter estimates and standard errors for the predictors in that model; and the total variance accounted for by that model. The grey cells indicate the effects of participant group. 
Table 7: Hierarchical Models of Verb Percentage in Children's Vocabularies between 0 and 430 words

\begin{tabular}{|c|c|c|c|c|c|c|}
\hline & & Parameter & $\begin{array}{l}\text { Unconditional } \\
\text { Model }\end{array}$ & $\begin{array}{c}\text { Vocabulary } \\
\text { Growth Model }\end{array}$ & $\begin{array}{c}\text { Vocabulary } \\
\text { Growth Model } 2\end{array}$ & $\begin{array}{c}\text { Vocabulary } \\
\text { Growth Model } 3\end{array}$ \\
\hline \multicolumn{7}{|l|}{ Fixed Effects } \\
\hline Initial percentage & Intercept & $\gamma_{00}$ & $\begin{array}{l}7.94 * * \\
(0.654)\end{array}$ & $\begin{array}{l}2.39 * \\
(0.952)\end{array}$ & $\begin{array}{c}2.00 \\
(1.04)\end{array}$ & $\begin{array}{l}2.38^{*} \\
(0.956)\end{array}$ \\
\hline$\pi_{0 \mathrm{i}}$ & $\begin{array}{l}\text { Group: preschooler } \\
\text { relative to infant }\end{array}$ & $\gamma_{01}$ & & & $\begin{array}{c}1.09 \\
(1.39)\end{array}$ & \\
\hline Rate of Change & Intercept & $\gamma_{10}$ & & $\begin{array}{l}\mathbf{0 . 0 3 6 * *} \\
(0.004)\end{array}$ & $\begin{array}{l}0.036^{* *} \\
(0.004)\end{array}$ & $\begin{array}{c}0.038^{* *} \\
(0.005)\end{array}$ \\
\hline$\pi_{2 \mathrm{i}}$ & $\begin{array}{l}\text { Group: preschooler } \\
\text { relative to infant }\end{array}$ & $\gamma_{11}$ & & & & $\begin{array}{l}-0.005 \\
(0.006)\end{array}$ \\
\hline \multicolumn{7}{|c|}{ Variance Components } \\
\hline Level 1 & Within person & $\sigma_{\varepsilon}^{2}$ & $31.03^{* *}$ & $6.71 * *$ & $6.71 * *$ & $6.69^{* *}$ \\
\hline \multirow[t]{2}{*}{ Level 2} & Initial percentage & $\sigma_{0}^{2}$ & $4.81^{* *}$ & $15.86^{* *}$ & $14.49^{* *}$ & $15.95^{* *}$ \\
\hline & Rate of change & $\sigma_{1}^{2}$ & & $0.0032 * *$ & $0.0032 * *$ & $0.0030 * *$ \\
\hline \multicolumn{7}{|c|}{ Pseudo R2 statistic and Goodness-of-fit } \\
\hline & $\mathrm{R}_{\mathrm{y}, \mathrm{y}}^{2}$ & & & 0.555 & 0.566 & 0.545 \\
\hline & Deviance & & 1108.67 & 914.03 & 913.44 & 913.53 \\
\hline & AIC & & 1114.67 & 926.03 & 927.44 & 927.53 \\
\hline & $\mathrm{BIC}$ & & 1124.08 & 944.85 & 949.39 & 949.48 \\
\hline & \# of parameters & & 3 & 6 & 7 & 7 \\
\hline
\end{tabular}

$* \mathrm{p}<.05, * * \mathrm{p}<.005$. Outlined cells indicate the model selected on the basis of fit; the parameter estimates and standard errors for the predictors in that model; and the total variance accounted for by that model. The grey cells indicate the effects of participant group. 
Table 8: Hierarchical Models of Adjective Percentage in Children's Vocabularies between 0 and 430 words

\begin{tabular}{|c|c|c|c|c|c|c|c|}
\hline & & Parameter & $\begin{array}{l}\text { Unconditional } \\
\text { Model }\end{array}$ & $\begin{array}{c}\text { Vocabulary } \\
\text { Growth Model }\end{array}$ & $\begin{array}{c}\text { Vocabulary } \\
\text { Growth Model } 2\end{array}$ & $\begin{array}{c}\text { Vocabulary } \\
\text { Growth Model } 3\end{array}$ & $\begin{array}{c}\text { Vocabulary } \\
\text { Growth Model } 4\end{array}$ \\
\hline \multicolumn{8}{|l|}{$\underline{\text { Fixed Effects }}$} \\
\hline Initial percentage & Intercept & $\gamma_{00}$ & $\begin{array}{l}6.81^{* *} \\
(0.552)\end{array}$ & $\begin{array}{l}4.65^{* *} \\
(0.686)\end{array}$ & $\begin{array}{l}3.67 * * \\
(0.682)\end{array}$ & $\begin{array}{l}4.51^{* *} \\
(0.666)\end{array}$ & $\begin{array}{l}3.56^{* *} \\
(0.752)\end{array}$ \\
\hline$\pi_{0 \mathrm{i}}$ & $\begin{array}{l}\text { Group: preschooler } \\
\text { relative to infant }\end{array}$ & $\gamma_{01}$ & & & $\begin{array}{c}2.61 * \\
(0.850) \\
\end{array}$ & & $\begin{array}{l}3.11^{*} \\
(1.38)\end{array}$ \\
\hline Rate of Change & Intercept & $\gamma_{10}$ & & $\begin{array}{c}0.014^{* *} \\
(0.002)\end{array}$ & $\begin{array}{l}0.014 * * \\
(0.002) \\
\end{array}$ & $\begin{array}{c}0.012^{* *} \\
(0.002)\end{array}$ & $\begin{array}{c}0.015^{* *} \\
(0.002)\end{array}$ \\
\hline$\pi_{2 \mathrm{i}}$ & $\begin{array}{l}\text { Group: preschooler } \\
\text { relative to infant }\end{array}$ & $\gamma_{11}$ & & & & $\begin{array}{l}0.006^{*} \\
(0.003)\end{array}$ & $\begin{array}{l}-0.002 \\
(0.005)\end{array}$ \\
\hline \multicolumn{8}{|c|}{ Variance Components } \\
\hline Level 1 & Within person & $\sigma_{\varepsilon}^{2}$ & $11.29^{* *}$ & $7.67 * *$ & $7.70 * *$ & $7.76^{* *}$ & $7.68 * *$ \\
\hline \multirow[t]{2}{*}{ Level 2} & Initial percentage & $\sigma_{0}^{2}$ & $4.89 * *$ & $76.82 * *$ & $4.69 * *$ & $6.08^{* *}$ & $4.82 * *$ \\
\hline & Rate of change & $\sigma_{1}^{2}$ & & $0.00002 *$ & $0.00001 *$ & $0.00002 *$ & $0.00001^{*}$ \\
\hline \multicolumn{8}{|c|}{ Pseudo R2 statistic and Goodness-of-fit } \\
\hline & $\mathrm{R}_{\mathrm{y}, \mathrm{y}}^{2}$ & & & 0.279 & 0.343 & 0.321 & 0.341 \\
\hline & Deviance & & 947.64 & 886.86 & 878.26 & 883.23 & 878.06 \\
\hline & AIC & & 953.64 & 898.86 & 892.26 & 897.23 & 894.06 \\
\hline & $\mathrm{BIC}$ & & 963.05 & 917.67 & 914.21 & 919.18 & 919.14 \\
\hline & \# of parameters & & 3 & 6 & 7 & 7 & 8 \\
\hline
\end{tabular}


Table 9: Hierarchical Models of the Proportion of the Adjectives on the Checklist that the Child Knows. Adjectives were divided into: behavior \& internal states, colors, and other descriptors.

\begin{tabular}{|c|c|c|c|c|c|c|c|c|}
\hline & & & $\underline{\text { Behavior an }}$ & nternal States & & & Other D & criptors \\
\hline & & Parameter & $\begin{array}{l}\text { Vocabulary } \\
\text { Growth } \\
\text { Model }\end{array}$ & $\begin{array}{c}\text { Vocabulary } \\
\text { Growth } \\
\text { Model 2 } \\
\end{array}$ & $\begin{array}{c}\text { Vocabulary } \\
\text { Growth } \\
\text { Model } \\
\end{array}$ & $\begin{array}{c}\text { Vocabulary } \\
\text { Growth } \\
\text { Model } 2\end{array}$ & $\begin{array}{l}\text { Vocabulary } \\
\text { Growth } \\
\text { Model }\end{array}$ & $\begin{array}{c}\text { Vocabulary } \\
\text { Growth } \\
\text { Model } 2 \\
\end{array}$ \\
\hline Fixed Effects & & & & & & & & \\
\hline Initial percentage & Intercept & $\gamma_{00}$ & $\begin{array}{c}-5.73 * * \\
(1.13)\end{array}$ & $\begin{array}{l}-5.14 * * \\
(1.05)\end{array}$ & $\begin{array}{r}2.59 \\
(3.15) \\
\end{array}$ & $\begin{array}{c}4.67 \\
(3.68)\end{array}$ & $\begin{array}{c}-2.53 * * \\
(.771)\end{array}$ & $\begin{array}{l}-3.56 * * \\
(.776) \\
\end{array}$ \\
\hline$\pi_{0 \mathrm{i}}$ & $\begin{array}{l}\text { Group: preschooler } \\
\text { relative to infant }\end{array}$ & $\gamma_{01}$ & & & & $\begin{array}{l}-7.79 \\
(7.24)\end{array}$ & & $\begin{array}{l}4.68^{*} \\
(1.64) \\
\end{array}$ \\
\hline Rate of Change & Intercept & $\gamma_{10}$ & $\begin{array}{l}0.133^{* *} \\
(0.016)\end{array}$ & $\begin{array}{l}0.100 * * \\
(0.014)\end{array}$ & $\begin{array}{l}0.221 * * \\
(0.017) \\
\end{array}$ & $\begin{array}{l}0.218^{* *} \\
(0.022)\end{array}$ & $\begin{array}{l}0.146^{* *} \\
(0.007)\end{array}$ & $\begin{array}{l}0.142 * * \\
(0.007) \\
\end{array}$ \\
\hline$\pi_{2 \mathrm{i}}$ & $\begin{array}{l}\text { Group: preschooler } \\
\text { relative to infant }\end{array}$ & $\gamma_{11}$ & & $\begin{array}{l}0.078^{* * *} \\
(0.018) \\
\end{array}$ & & $\begin{array}{c}0.015 \\
(0.039)\end{array}$ & & \\
\hline Variance Compon & & & & & & & & \\
\hline Level 1 & Within person & $\sigma_{\varepsilon}^{2}$ & $56.76^{* *}$ & $57.81 \% *$ & $342.02 * *$ & $340.17 * *$ & $28.72^{* *}$ & $27.08^{* * *}$ \\
\hline Level 2 & Initial percentage & $\sigma_{0}^{2}$ & $7.48^{*}$ & 3.24 & 73.90* & $66.05^{*}$ & .730 & .548 \\
\hline & Rate of change & $\sigma^{2}{ }_{1}$ & $0.00451^{* *}$ & $0.00192 * *$ & $.00275^{* *}$ & $0.00290^{* *}$ & $.00064 * *$ & $.00068^{* * *}$ \\
\hline Pseudo R2 statisti & Goodness-of-fit & & & & & & & \\
\hline & $R_{y, y}^{2}$ & & 0.622 & 0.788 & 0.609 & 0.615 & 0.846 & 0.853 \\
\hline & Deviance & & 1174.75 & 1160.94 & 1448.90 & 1447.72 & 1051.52 & 1043.51 \\
\hline & AIC & & 1186.75 & 1174.94 & 1460.90 & 1461.72 & 1063.52 & 1057.51 \\
\hline & BIC & & 1205.56 & 1196.89 & 1479.71 & 1483.67 & 1082.33 & 1079.46 \\
\hline & \# of parameters & & 6 & 7 & 6 & 7 & 6 & 7 \\
\hline
\end{tabular}

$* \mathrm{p}<.05, * * \mathrm{p}<.005$. Outlined cells indicate the model selected on the basis of fit; the parameter estimates and standard errors for the predictors in that model; and the total variance accounted for by that model. The grey cells indicate the effects of participant group. 


\section{Table 10: Hierarchical Models of Time Words as a Percentage of all Words in}

Children's Vocabularies between 0 and 430 words

\begin{tabular}{|c|c|c|c|c|c|c|c|}
\hline & & Parameter & $\begin{array}{l}\text { Unconditional } \\
\text { Model }\end{array}$ & $\begin{array}{l}\text { Vocabulary } \\
\text { Growth Model }\end{array}$ & $\begin{array}{c}\text { Vocabulary } \\
\text { Growth Model } 2 \\
\end{array}$ & $\begin{array}{c}\text { Vocabulary } \\
\text { Growth Model } 3\end{array}$ & $\begin{array}{c}\text { Vocabulary } \\
\text { Growth Model } 4\end{array}$ \\
\hline \multicolumn{8}{|l|}{$\underline{\text { Fixed Effects }}$} \\
\hline Initial percentage & Intercept & $\gamma_{00}$ & $\begin{array}{l}4.45^{* *} \\
(0.837)\end{array}$ & $2.24 \quad(1.30)$ & $\begin{array}{l}0.130 \\
(1.22) \\
\end{array}$ & $\begin{array}{l}1.95 \\
(1.23)\end{array}$ & $\begin{array}{c}-.147 \\
(0.565)\end{array}$ \\
\hline$\pi_{0 \mathrm{i}}$ & $\begin{array}{l}\text { Group: preschooler } \\
\text { relative to infant }\end{array}$ & $\gamma_{01}$ & & & $\begin{array}{l}5.12 * * \\
(1.15)\end{array}$ & & $\begin{array}{c}6.16 \\
(3.32)\end{array}$ \\
\hline Rate of Change & Intercept & $\gamma_{10}$ & & $\begin{array}{l}0.016^{* *} \\
(0.004)\end{array}$ & $\begin{array}{l}0.017^{* *} \\
(0.004) \\
\end{array}$ & $\begin{array}{l}0.012 * \\
(0.004)\end{array}$ & $\begin{array}{l}0.018 * * \\
(0.003)\end{array}$ \\
\hline$\pi_{2 \mathrm{i}}$ & $\begin{array}{l}\text { Group: preschooler } \\
\text { relative to infant }\end{array}$ & $\gamma_{11}$ & & & & $\begin{array}{l}0.014^{* *} \\
(0.004)\end{array}$ & $\begin{array}{l}-0.004 \\
(0.010)\end{array}$ \\
\hline \multicolumn{8}{|c|}{$\underline{\text { Variance Components }}$} \\
\hline Level 1 & Within person & $\sigma_{\varepsilon}^{2}$ & $21.83 * *$ & $15.92 * *$ & $15.61 * *$ & $15.67^{* *}$ & $15.52 * *$ \\
\hline \multirow[t]{2}{*}{ Level 2} & Initial percentage & $\sigma_{0}^{2}$ & $11.74^{* *}$ & $27.42 * *$ & $19.69^{* *}$ & $27.16^{* *}$ & $20.79 * *$ \\
\hline & Rate of change & $\sigma_{1}^{2}$ & & $0.00010^{* *}$ & $0.00012 * *$ & $0.00018^{* *}$ & $0.00013^{* *}$ \\
\hline \multicolumn{8}{|c|}{ Pseudo R2 statistic and Goodness-of-fit } \\
\hline & $R_{y, y}^{2}$ & & & 0.211 & 0.291 & 0.288 & 0.283 \\
\hline & Deviance & & 1066.12 & 1024.27 & 1008.60 & 1014.36 & 1008.46 \\
\hline & $\mathrm{AIC}$ & & 1072.12 & 1036.27 & 1022.60 & 1028.36 & 1024.46 \\
\hline & $\mathrm{BIC}$ & & 1081.53 & 1055.08 & 1044.55 & 1050.31 & 1049.54 \\
\hline & \# of parameters & & 3 & 6 & 7 & 7 & 8 \\
\hline
\end{tabular}


Table 11: Hierarchical Models of the Proportion of the Time Words on the Checklist that the Child Knows. Time Words were divided into: 1) terms used for future or past events and 2) terms often used for present events

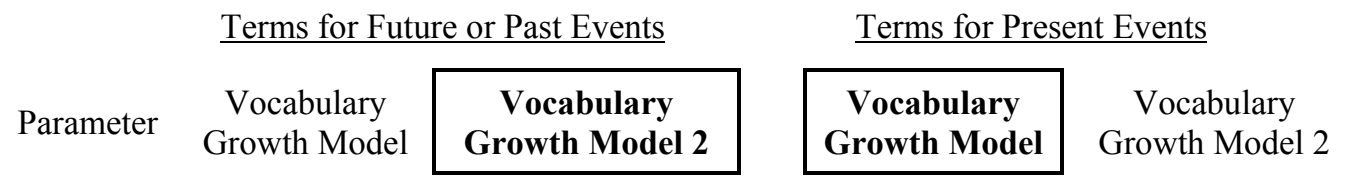

\section{$\underline{\text { Fixed Effects }}$}

$\begin{array}{ll}\text { Initial percentage } & \text { Intercept } \\ \text { Rate of Change } & \begin{array}{l}\text { Intercept } \\ \text { Group: preschoole } \\ \text { relative to infant }\end{array} \\ \pi_{2 \mathrm{i}} & \text { Within person } \\ \text { Variance Components } & \text { Initial percentage } \\ \text { Level 1 } & \text { Rate of change }\end{array}$

$\gamma_{00}$
$\gamma_{10}$
$\gamma_{11}$

$$
-2.05^{*}
$$$$
(.760)
$$$$
0.041 * *
$$$$
(0.010)
$$
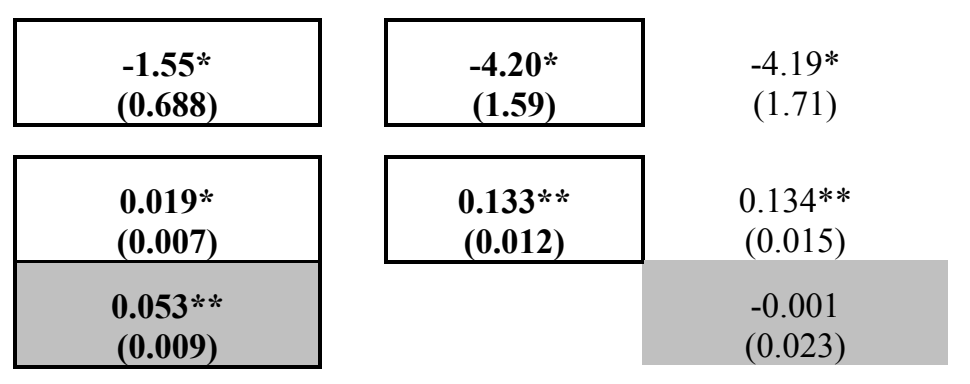

$\begin{array}{cc}\sigma_{\varepsilon}^{2} & 23.73^{* *} \\ \sigma_{0}^{2} & 4.16 \\ \sigma^{2}{ }_{1} & 0.00177^{* *}\end{array}$

$$
\begin{gathered}
24.41 * * \\
1.63 \\
0.00053 * *
\end{gathered}
$$

$$
\begin{gathered}
178.14^{* *} \\
1.03 \\
0.00156^{* *}
\end{gathered}
$$$$
180.28 * *
$$$$
.755
$$$$
0.00151^{* *}
$$

$\underline{\text { Pseudo R2 statistic and Goodness-of-fit }}$

$$
\begin{aligned}
& \mathrm{R}_{\mathrm{y}, \mathrm{y}}^{2} \\
& \text { Deviance } \\
& \text { AIC } \\
& \text { BIC } \\
& \text { \# of parameters }
\end{aligned}
$$

$$
\begin{gathered}
0.216 \\
1030.92 \\
1042.92 \\
1061.73
\end{gathered}
$$$$
6
$$

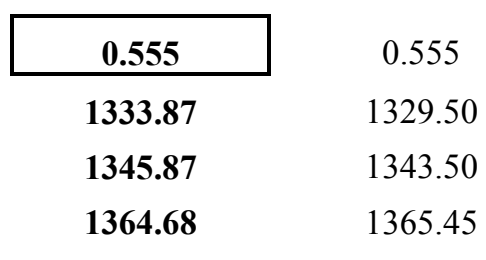

6

1365.45

7

7

$* \mathrm{p}<.05, * * \mathrm{p}<.005$. Outlined cells indicate the model selected on the basis of fit; the parameter estimates and standard errors for the predictors in that model; and the total variance accounted for by that model. The grey cells indicate the effects of participant group. 
Figure 1: Vocabulary growth in adopted infants and preschoolers. Language onset was defined as the estimated time at which each child had a vocabulary of 20 words.

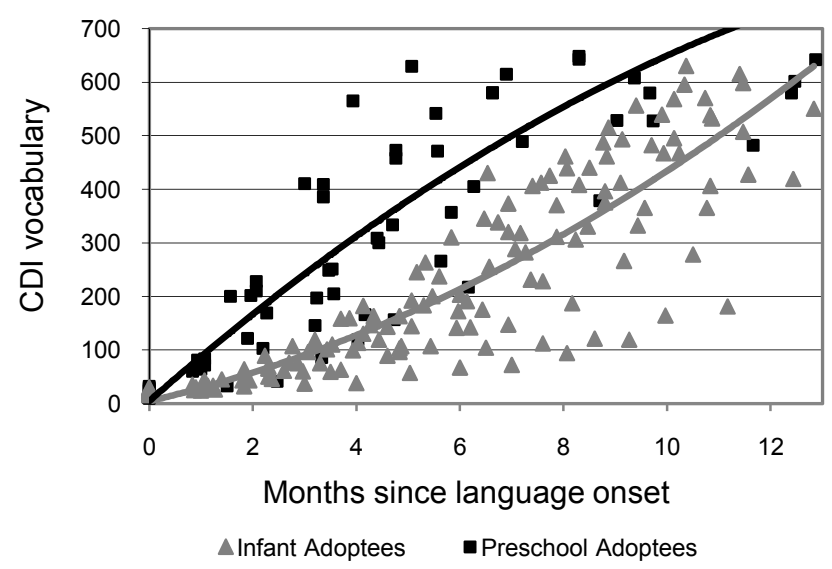


Figure 2: The proportion of social words in the children's vocabularies declines between 0 and 430 words.

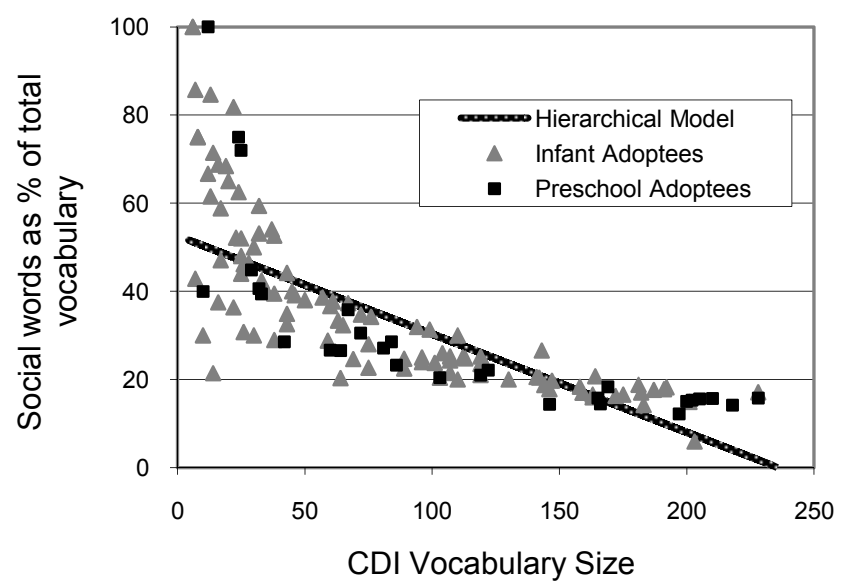


Figure 3: The proportion of nouns in children's vocabularies a) rises from 0 to 230 words and b) falls from 200 to 610 words.
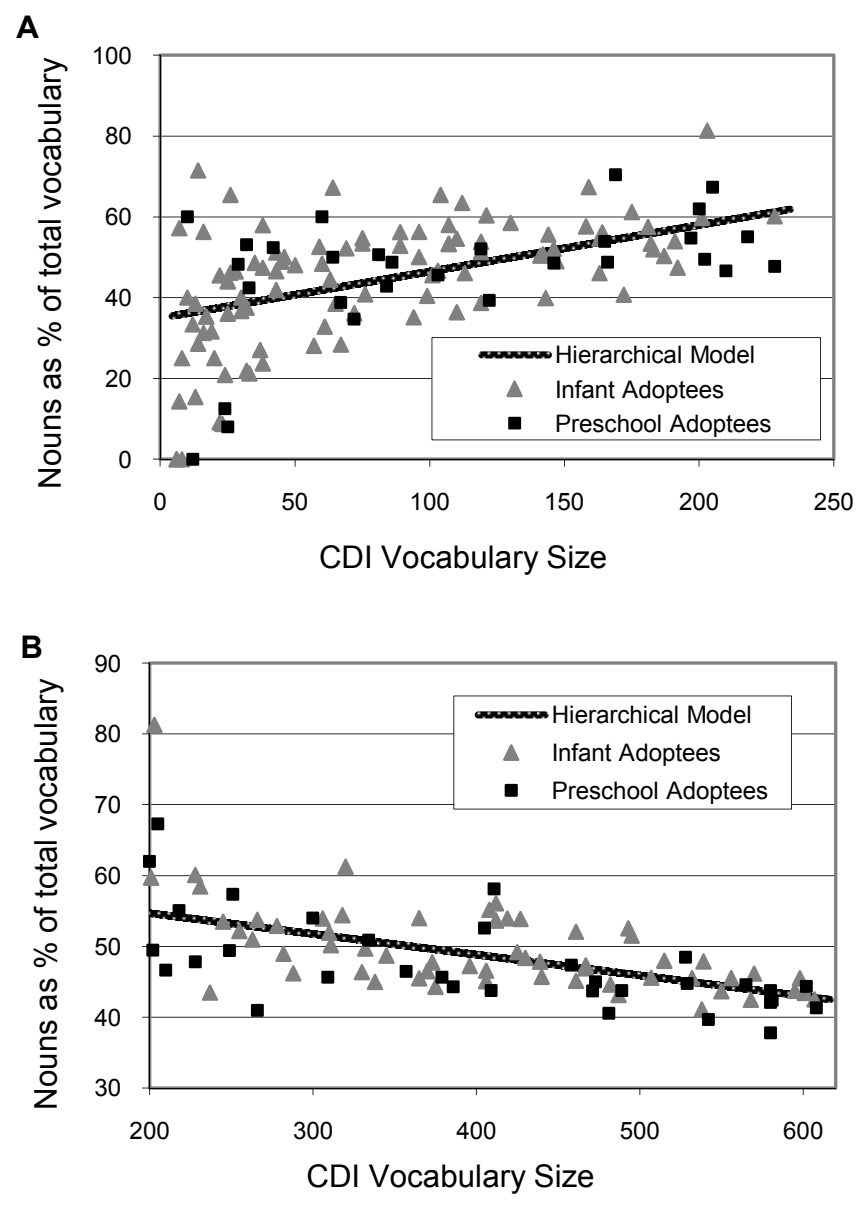
Figure 4: The proportion of verbs in children's vocabularies rises from 0 to 430 words.

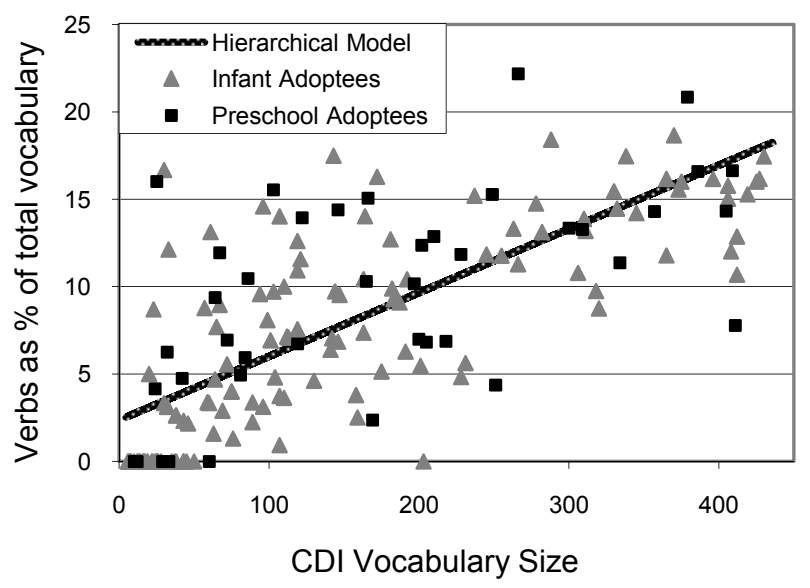


Figure 5: The proportion of adjectives in children's vocabularies rises from 0 to 430 words.

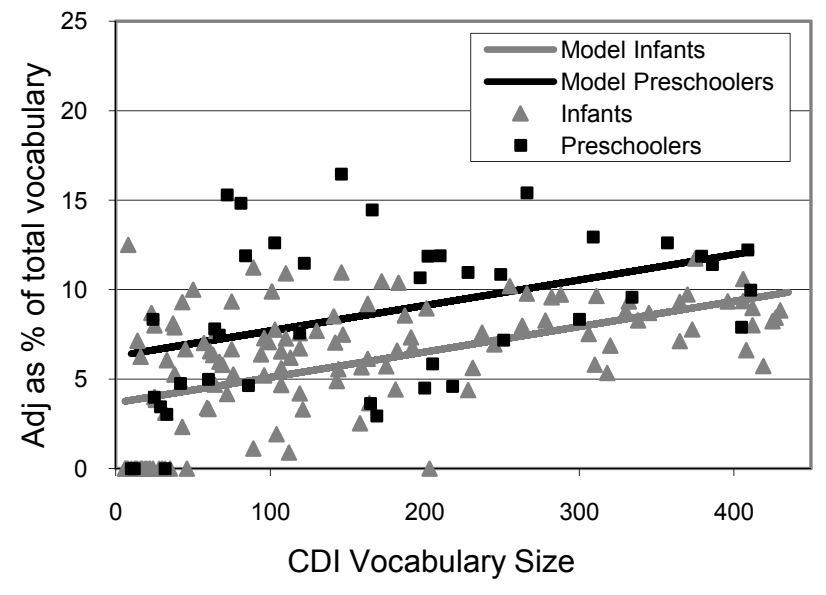


Figure 6: The percentage of the adjectives on the checklist that children know divided into three categories: a) adjectives regulating behavior or describing internal states; b) color words; c) all other descriptors.
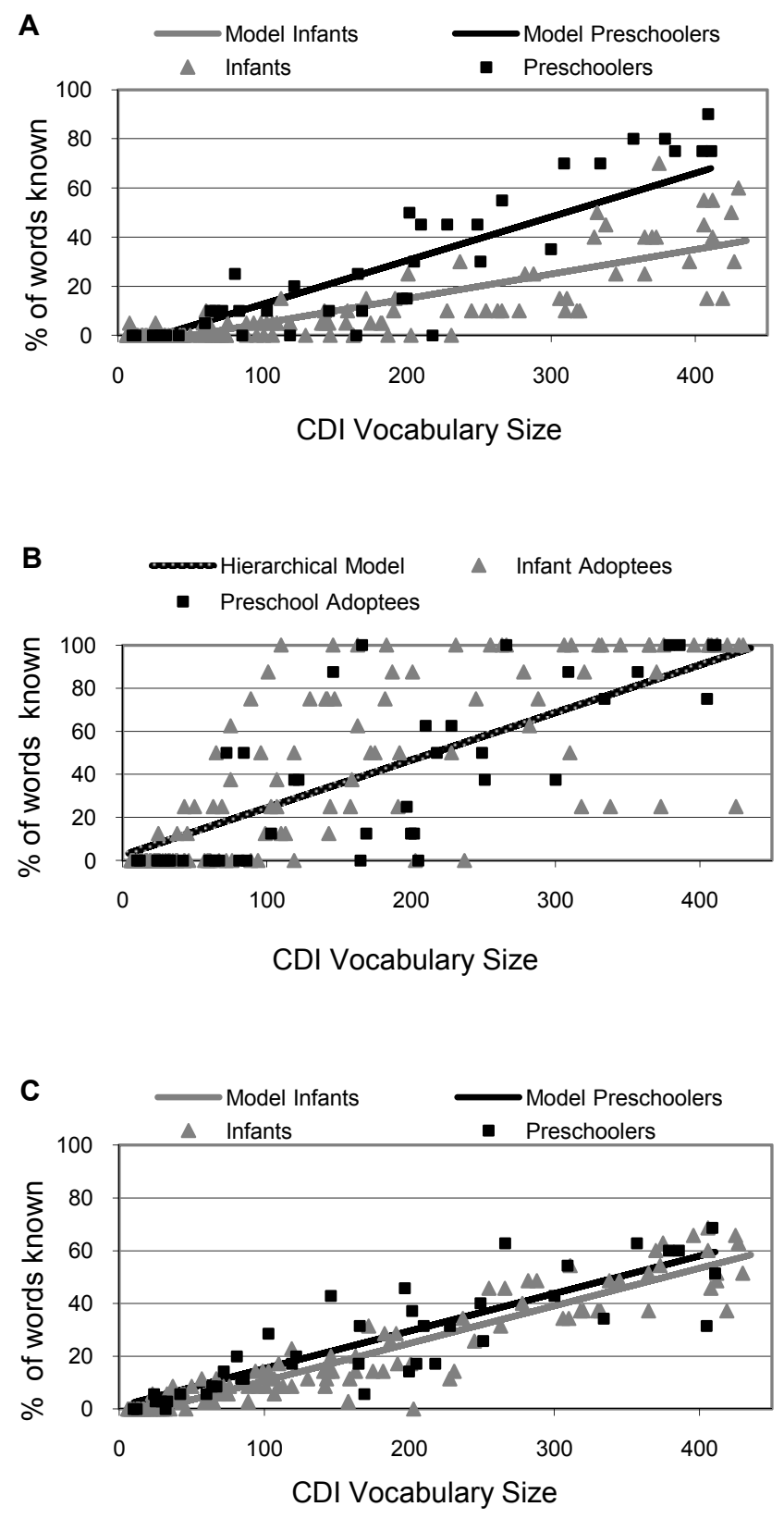
Figure 7: The proportion of time words in children's vocabularies between 0 and 430 words.

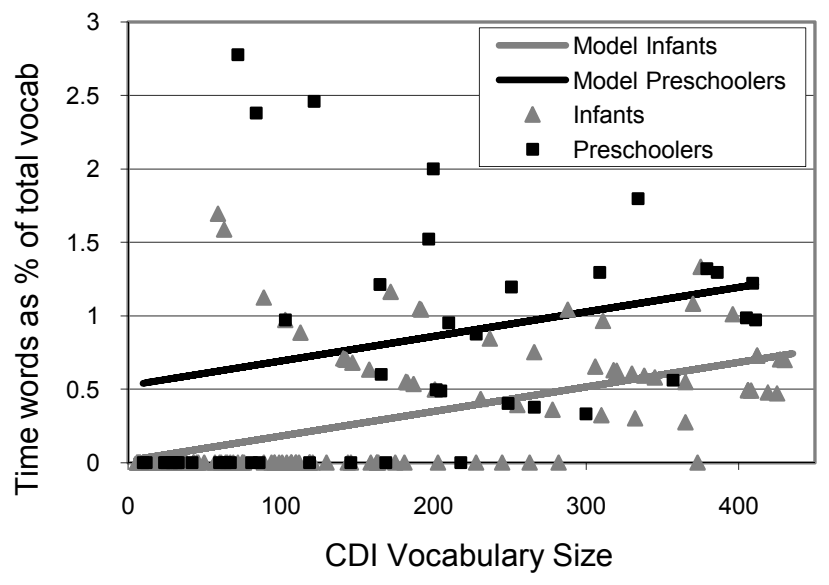


Figure 8: The percentage of the time words on the checklist that children know divided into two categories: a) words that typically refer to events in the future or past and b) time words that easily refer to events in the present.
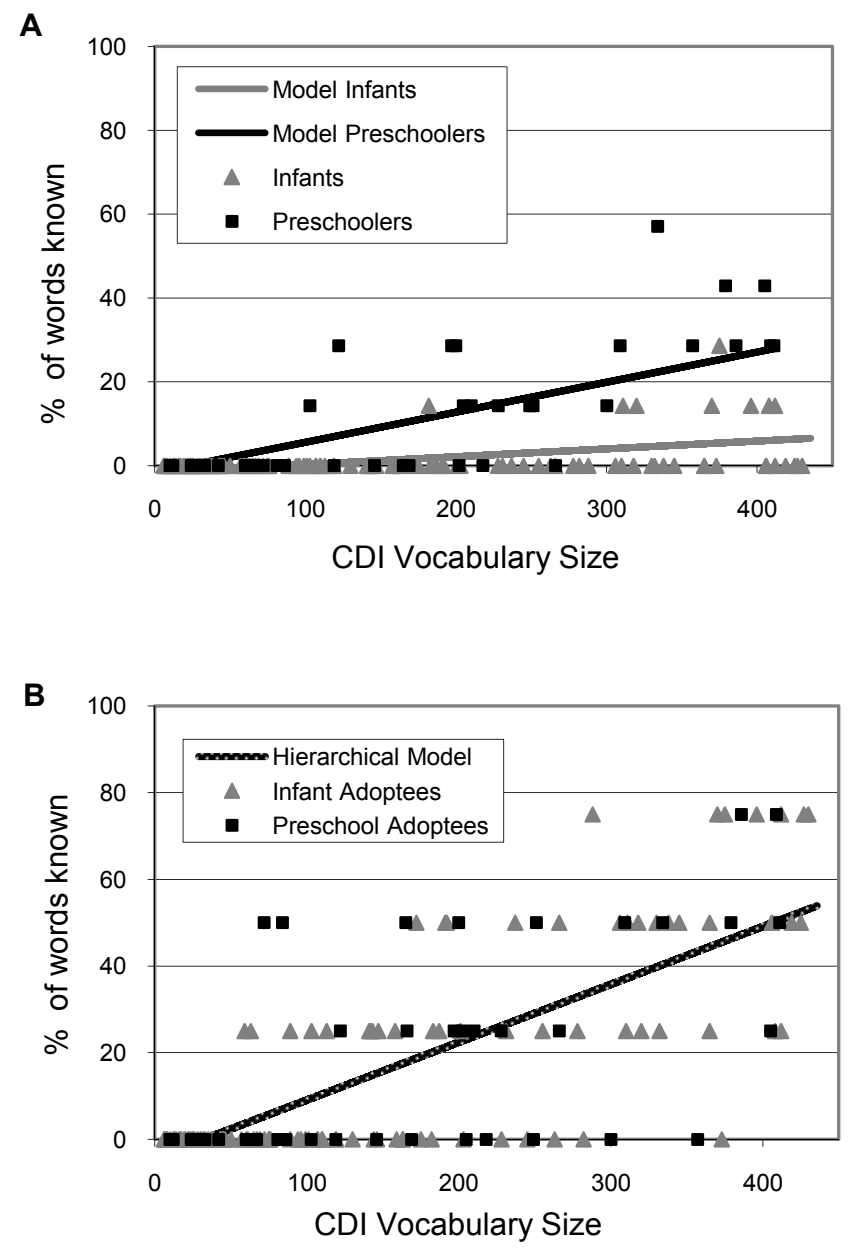
Figure 9: Mean vocabulary size at the onset of word combinations in adopted infants and preschoolers.

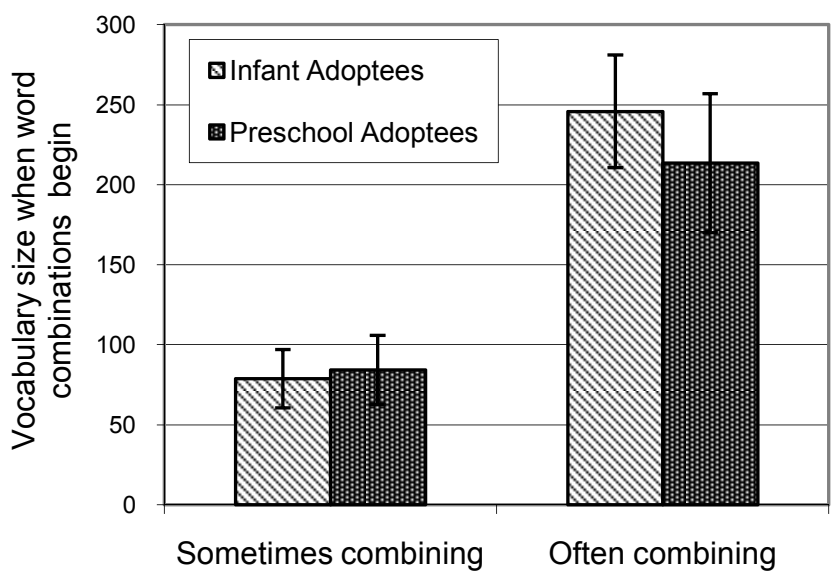


